
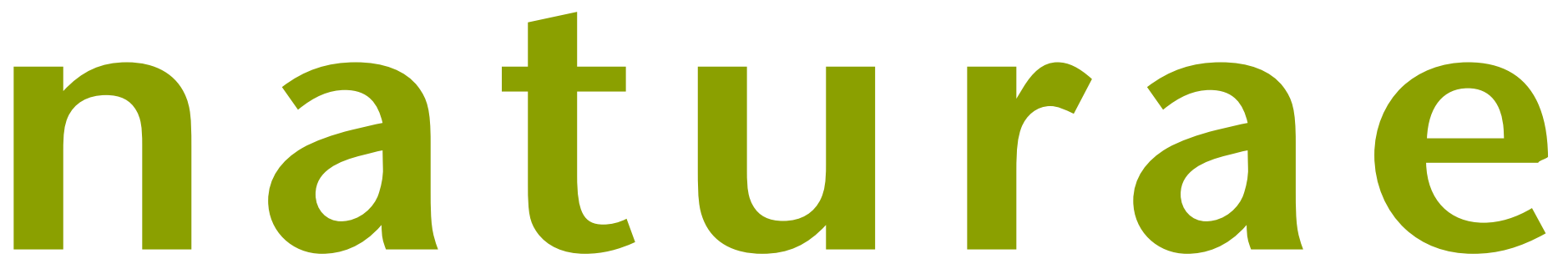

$2020 \cdot 2$

\title{
Synthèse des connaissances des Mantodea de Guyane
}

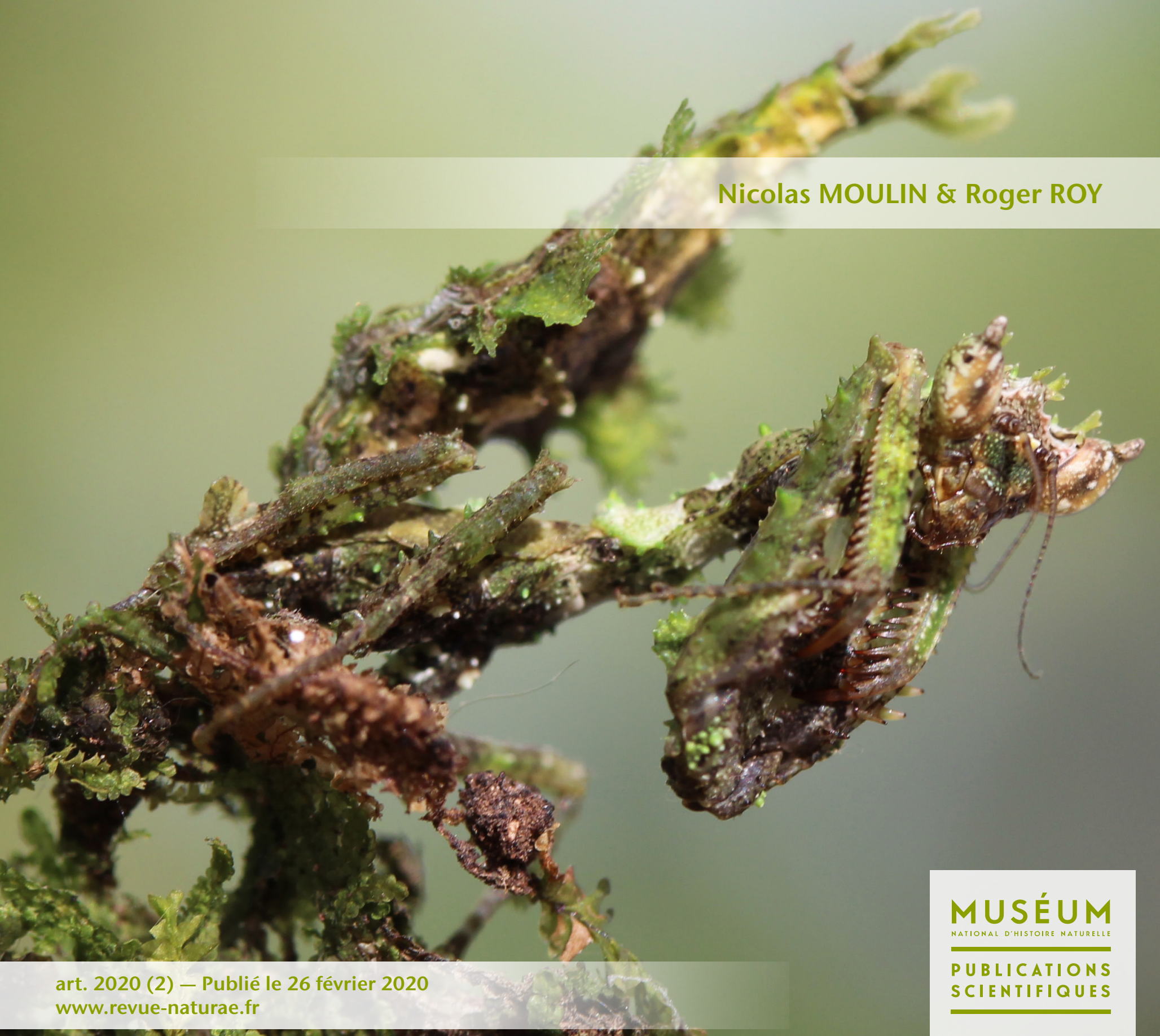


DiRECTEUR DE LA PUbliCATION: Bruno David,

Président du Muséum national d'Histoire naturelle

RÉDACTEUR EN CHEF / EDITOR-IN-CHIEF: Jean-Philippe Siblet

ASSISTANTE DE RÉDACTION / ASSISTANT EDITOR: Sarah Figuet (naturae@mnhn.fr)

Mise EN PAGE / PAGE LAYOUT: Sarah Figuet

COMITÉ SCIENTIFIQUE / SCIENTIFIC BOARD:

Luc Abbadie (UPMC, Paris)

Luc Barbier (Parc naturel régional des caps et marais d'Opale, Colembert)

Aurélien Besnard (CEFE, Montpellier)

Vincent Boullet (Expert indépendant flore/végétation, Frugières-le-Pin)

Hervé Brustel (École d'ingénieurs de Purpan, Toulouse)

Patrick De Wever (MNHN, Paris)

Thierry Dutoit (UMR CNRS IMBE, Avignon)

Éric Feunteun (MNHN, Dinard)

Romain Garrouste (MNHN, Paris)

Grégoire Gautier (DRAAF Occitanie, Toulouse)

Olivier Gilg (Réserves naturelles de France, Dijon)

Frédéric Gosselin (Irstea, Nogent-sur-Vernisson)

Patrick Haffner (UMS PatriNat, Paris)

Frédéric Hendoux (MNHN, Paris)

Xavier Houard (OPIE, Guyancourt)

Isabelle Leviol (MNHN, Concarneau)

Francis Meunier (Conservatoire d'espaces naturels - Picardie, Amiens)

Serge Muller (MNHN, Paris)

Francis Olivereau (DREAL Centre, Orléans)

Laurent Poncet (UMS PatriNat, Paris)

Nicolas Poulet (AFB, Vincennes)

Jean-Philippe Siblet (UMS PatriNat, Paris)

Laurent Tillon (ONF, Paris)

Julien Touroult (UMS PatriNat, Paris)

COUVERTURE / COVER:

Jeune Pseudacanthops spinulosa (Saussure, 1870) observé le 2 mars 2019 sur la Montagne des Chevaux. Crédit photo: J. Lapéze.

Naturae est une revue en flux continu publiée par les Publications scientifiques du Muséum, Paris

Naturae is a fast track journal published by the Museum Science Press, Paris

Les Publications scientifiques du Muséum publient aussi / The Museum Science Press also publish:

Adansonia, Zoosystema, Anthropozoologica, European Journal of Taxonomy, Geodiversitas, Cryptogamie sous-sections Algologie, Bryologie, Mycologie.

Diffusion - Publications scientifiques Muséum national d'Histoire naturelle

CP 41 - 57 rue Cuvier F-75231 Paris cedex 05 (France)

Tél.: 33 (0)1 40794805 / Fax: 33 (0)1 40793840

diff.pub@mnhn.fr / http://sciencepress.mnhn.fr

(C) Publications scientifiques du Muséum national d'Histoire naturelle, Paris, 2020

ISSN (électronique / electronic): 1638-9387 


\title{
Synthèse des connaissances des Mantodea de Guyane
}

\author{
Nicolas MOULIN \\ Attaché honoraire du Muséum national d'Histoire naturelle, \\ 82 route de l'école, Hameau de Saveaumare, F-76680 Montérolier (France) \\ nmentomo@gmail.com \\ Roger ROY \\ Attaché honoraire du Muséum national d'Histoire naturelle, \\ case postale 56, 57 rue Cuvier, F-5231 Paris cedex 05 (France) \\ rroy@mnhn.fr
}

Soumis le 13 août 2019 | Accepté le 7 octobre 2019 | Publié le 26 février 2020

MOTS CLÉS

Outre-Mer, Mantes,

biodiversité, écologie, inventaire codes-barres ADN, pseudogènes.
Moulin N. \& Roy R. 2020. - Synthèse des connaissances des Mantodea de Guyane. Naturae 2020 (2): 31-53. https://doi.org/10.5852/naturae2020a2

\section{RÉSUMÉ}

Cet article fait le point sur les connaissances des Mantes en Guyane. Il compile à la fois des données plus ou moins anciennes de la collection générale du bâtiment d'entomologie au Muséum national d'Histoire naturelle (MNHN, Paris), ainsi que des données plus récentes provenant de la collection privée du premier auteur, des échantillonnages de la Société Entomologique Antilles-Guyane (SEAG) et des collectes provenant de la mission scientifique "La Planète Revisitée» dans le massif du Mitaraka, en 2015. L’ensemble des données (4424 spécimens) ont été saisies sous CardObs (INPN - Inventaire national du Patrimoine naturel). Parmi ces données, 2448 spécimens, dont la technique de collecte est connue, ont été analysés afin de comprendre la répartition, l'abondance et l'écologie d'un grand nombre d'espèces de Mantes de Guyane. Le nombre d'espèces de Mantes recensées en Guyane s'élève actuellement à 90 espèces. 299 spécimens ont été séquencés à partir du gène mitochondrial Cytochrome Oxydase-I (COI) afin d'établir les fondations d'une bibliothèque de référence de barcodes ADN des Mantes de Guyane. 250 séquences ont été obtenues, lesquelles englobent 82 BINs («Barcode Index Number», assimilés à des espèces). À cette occasion, nous soulignons également le problème lié à la présence des pseudogènes nucléaires mitochondriaux (numts), un problème connu dans le séquençage des espèces d'Orthoptères, et la possibilité d'infections par Wolbachia. Enfin, nous discutons des implications taxonomiques possibles de nos résultats de séquençage $\mathrm{ADN}$ et des orientations de recherche futures.

\section{ABSTRACT}

Synthesis of the knowledge of Mantodea from French Guiana.

This article focuses on the knowledge of Mantodea in French Guiana. It compiles both old and recent data from the general collection of the entomology building at the Muséum national d'Histoire naturelle (MNHN, Paris), as well as more recent data from the private collection of the first author and samplings of the Société Entomologique Antilles-Guyane (SEAG) and samplings from the scientific mission "Our Planet Revisited" in the Mitaraka massif in 2015. All data (4424 specimens) 


\section{KEY WORDS \\ Overseas, \\ praying mantis, \\ biodiversity, ecology, \\ DNA barcoding, pseudogenes.}

were seized under CardObs (INPN - Inventaire national du Patrimoine naturel). Among these data, 2448 specimens, whose collection technique is known, were analyzed in order to understand the distribution, abundance and ecology of many species of Mantodea from French Guiana. The number of Mantodea species in French Guiana amounts to 90 species at present. 299 specimens were sequenced from the mitochondrial Cytochrome Oxidase-I (COI) gene to provide the foundation for a reference library of French Guiana Mantodea DNA barcodes. 250 sequences were obtained, which include 82 BINs ("Barcode Index Number", assimilated to species). We also highlight the problem of nuclear mitochondrial pseudogenes (numts), a known problem in the barcoding of orthopteran species, and the possibility of Wolbachia infections. Finally, we discuss the possible taxonomic implications of our barcoding results and point out future research directions.

\section{INTRODUCTION}

La Guyane, Département et Région d'Outre-Mer (DROM) d'une superficie de $83846 \mathrm{~km}^{2}$ (15\% de la superficie de l'Hexagone), est le département français le plus boisé, avec $98 \%$ de la surface couverte de forêt équatoriale qui reste parmi la plus riche et la moins écologiquement fragmentée du monde. La forêt guyanaise héberge une Faune et une Flore remarquables (Charles-Dominique 2011; Vedel et al. 2013; Quartarollo \& Baglan 2016; Dewynter comm. pers.), en particulier une entomofaune très diversifiée (Tavakilian 1993; Gombauld et al. 2004; Brûlé \& Touroult 2014; Jourdan et al. 2014; Mortelmans \& Pollet 2018; Bellanger et al. 2018; Lupoli 2019; Roy 2019; Lapèze comm. pers.). Cette biodiversité entomologique a attiré de nombreux scientifiques et autres amateurs d'Insectes depuis la fin du 18e siècle (Gombauld et al. 2004; Brûlé \& Touroult 2014; Dewynter comm. pers.). Parmi les Insectes collectés, des prédateurs emblématiques ont été régulièrement collectés: les Mantes.

La première mention de Mantes présentes en Guyane se situe dans une publication de Fabricius (1787) avec Mantis perspicua Fabricius, 1787, espèce décrite à cette occasion, indiquée «habitat Cajennae». Cette même espèce est citée ensuite par Olivier (1792) en précisant «elle se trouve à Cayenne», puis à nouveau par Fabricius (1793), en répétant «habitat Cajennae». Fabricius (1798) ajoute Mantis lobata Fabricius, 1798, décrite à cette occasion, avec la même indication de provenance.

Il faut attendre Audinet-Serville (1831) pour que soit ajoutée Choeradodis laticollis Serville, 1831, décrite à cette occasion de Cayenne, et Thespis purpurascens Serville, 1831, également mentionnée de Cayenne. Puis le même auteur ajoute en 1838 huit autres espèces avec la même indication de provenance.

Saussure (1869) décrit Liturgousa cayennensis Saussure, 1869 de Cayenne et Acontista elegans Saussure, 1869 de "Guyana ", appellation ambiguë qui pourrait désigner l'ancienne Guyane britannique, ou l'actuel Suriname. L'année suivante (1870), il ajoute trois autres espèces de Guyana, dont deux au moins proviennent en fait de Guyane (française) avec les types au Muséum national d'Histoire naturelle (MNHN) à Paris: Acontista roseipennis Saussure, 1870 et Acanthops tuberculatus Saussure, 1870. Saussure (1871) liste cette fois 24 espèces en indiquant suivant les cas «La Guyane», «Cayenne» ou les deux à la suite. Étonnamment, les dix espèces citées précédemment de Cayenne par Audinet-Serville n'y figurent pas.

Westwood (1889) mentionne 41 espèces pour l'ensemble des Guyanes en précisant à chaque fois Guiana, Suriname ou Cayenne (13 fois), éventuellement deux de ces localisations, une seule fois avec la mention "Paramaribo", une autre avec la précision «Guiana Francesca». Nous trouvons encore 11 espèces mentionnées de Cayenne dans Saussure \& Zehntner (1894), puis 19 dans Kirby (1904).

Chopard (1910a) décrit dans une première publication, Zoolea multilobata Chopard, 1910 de Guyane française, puis dans une seconde, la même année Chopard (1910b), Thespis lemoulti Chopard, 1910 et Thespis maxima Chopard, 1910; avant une étude d'ensemble (1912) des espèces provenant du nord du territoire, avec 43 espèces répertoriées dont 12 nouvelles pour la Science, réparties en 24 genres.

Giglio-Tos (1927) mentionne 49 espèces, suivant les cas de Guyane ou de Guiane sans précision, mais par deux fois Cayenne et une fois Guyane anglaise.

La connaissance de la Faune des Mantes a peu évolué pendant la soixantaine d'années suivantes, et c'est ainsi que Terra (1995) ne répertorie que 56 espèces de "Guiana Francesa ". Le nombre d'espèces mentionnées de Guyane passe à 77 dans Ehrmann (2002), puis à 92 dans Agudelo Rondon et al. (2007) grâce à un renouveau dans les prospections, lesquelles se poursuivent jusqu'à aujourd'hui, en particulier avec les récoltes massives réalisées depuis 2007 principalement à la Montagne des Chevaux par la Société Entomologique Antilles-Guyane (SEAG) et celles plus localisées au massif du Mitaraka (extrême sud-ouest de la Guyane) dans le cadre de la mission de connaissance de la biodiversité, «La Planète Revisitée» (expéditions en 2015), organisée collaborativement par le MNHN et Pro-Natura International (Pascal et al. 2015; Touroult et al. 2018). Douze espèces ont été décrites par des spécimens uniquement connus de Guyane (autant qu'on le sache) et six espèces sont endémiques à sub-endémiques de Guyane (Brûlé \& Touroult 2014; Roy 2015, 2019).

Les données saisies sous CardObs permettent de cartographier l'ensemble des stations où des Mantes ont été collectées ces 250 dernières années. Elles permettent également d'évaluer les degrés d'abondance de chacune des espèces présentes. Ces 
données vont enrichir le référentiel taxonomique national (TAXREF: Gargominy et al. 2019) au nom de l'inventaire du patrimoine naturel de France (Inventaire national du Patrimoine naturel [INPN] - https://inpn.mnhn.fr, dernière consultation le 13 décembre 2019). Les données de la SEAG permettent d'analyser l'effet des différentes techniques d'échantillonnage sur les Mantes (sex-ratio, communauté d'espèces, etc.). Enfin, le séquençage ADN de 299 spécimens permet de mettre en place une première bibliothèque de référence de 250 séquences. Une large représentativité des espèces présentes en Guyane a été visée. Cela permet aussi de confirmer la validité taxonomique de certaines espèces en étudiant les codes-barres obtenus.

\section{MATÉRIEL ET MÉTHODES}

Suite à l'obtention d'un financement pour l'appel à projet INPN 2018 «Contribution à la connaissance naturaliste » par l'Unité mixte de Service PatriNat (AFB-CNRS-MNHN) dans le cadre de l'amélioration des connaissances sur les Mantes de Guyane, le premier auteur a rassemblé sur l'interface CardObs, entre juillet 2018 et mars 2019, les données du MNHN, les données identifiables à l'espèce sur photographie et celles provenant de sa collection personnelle; ainsi que les données plus clairsemées d'entomologistes amateurs éclairés. Les nombreuses stations où des Mantes ont été collectées, ou simplement observées, sont représentées sur une carte (Fig. 1) provenant de l'outil de gestion en ligne de données naturalistes, CardObs. Des photos in natura de Mantes (dont l'espèce est présente en Guyane) ont été compilées afin d'alimenter les fiches «Espèces» de l'INPN.

La majeure partie des données portant sur la Guyane ont été inspirées par la "Checklist of the Neotropical mantids" (Agudelo Rondon et al. 2007) et corrigées avec de nombreuses publications plus récentes mais éparses. La classification utilisée tient également compte des plus récents travaux dans le domaine (Svenson \& Whiting 2009; Rivera \& Svenson 2016; Schwarz \& Roy 2019), mais ne saurait être considérée comme définitive.

Seize techniques de collectes d'Insectes pratiquées par la SEAG ont été prises en compte. Quatre d'entre elles sont figurées (Fig. 2). Certaines techniques de la SEAG enrichissent la liste de celles déjà connues et décrites dans le manuel rédigé par Brannoch et al. (2017). La majeure partie d'entre elles est basée sur l'attraction par la lumière (UV, bleue, rose) dans un système aérien d'interception (Fig. 2; Tableau 1).

Les données obtenues par les échantillonnages continus de la SEAG en Guyane sont analysées plus particulièrement afin de mettre en évidence les différentes communautés d'espèces de Mantes selon les techniques de collecte, les localités et la saisonnalité de certaines espèces (nécessité d'avoir une espèce abondante afin d'obtenir des fluctuations significatives sur 12 mois). La répartition annuelle des espèces avec plus de 75 spécimens collectés (10 espèces) est représentée. Ce sont les espèces les plus communes. Elles sont facilement reconnaissables.

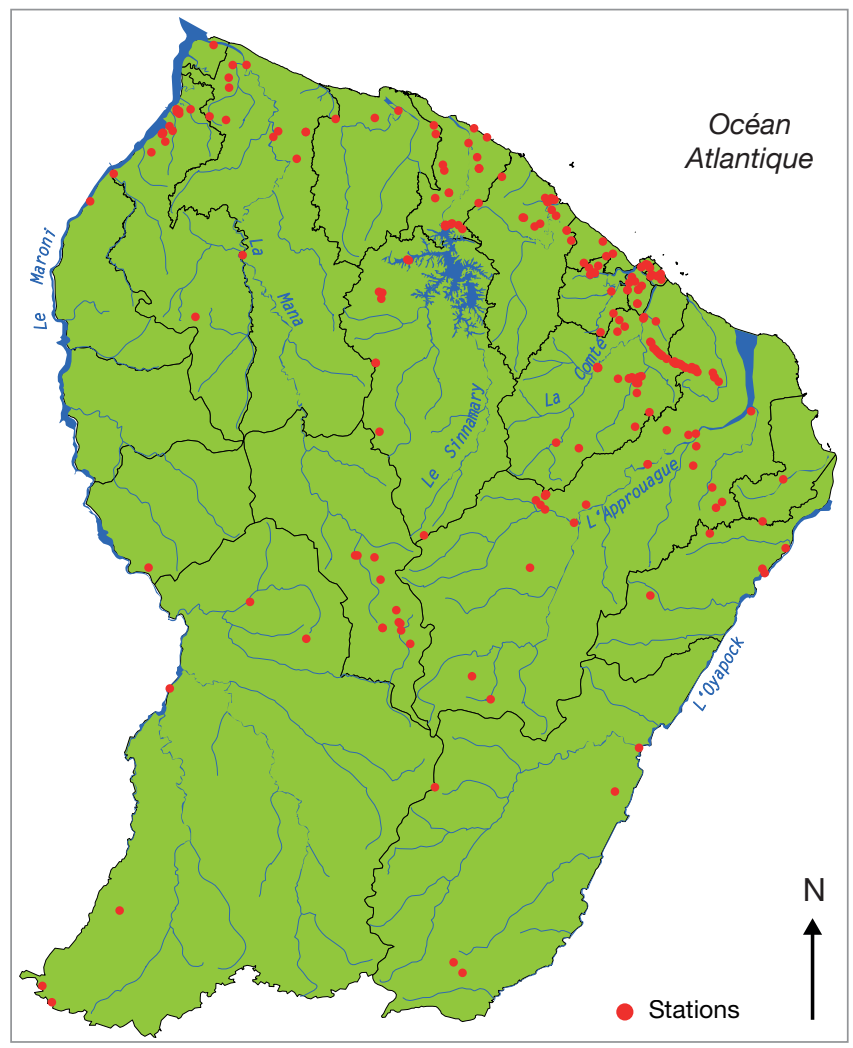

FIG. 1. - Distribution des stations enregistrées sous CardObs ayant des données sur les Mantodea.

Il est connu que les Mantes sont attirées par la lumière avec un sex-ratio très fortement déséquilibré en faveur des mâles. Les techniques d'échantillonnage de la SEAG, basées majoritairement sur l'attraction lumineuse, confirment cette observation.

Additionnellement, la diversité régionale des Mantodea a été analysée en représentant les courbes de raréfaction globales de la richesse spécifique et de la couverture d'échantillonnage ainsi que leurs extrapolations dans une situation hypothétique où l'effort d'échantillonnage (c'est-à-dire le nombre de spécimens enregistrés sous CardObs) aurait été multiplié par deux (Fig. 3). La couverture d'échantillonnage mesure la proportion du nombre total d'individus d'une communauté écologique ou d'une région géographique qui appartiennent aux espèces représentées dans l'échantillon. En d'autres termes, il s'agit d'un indice permettant de mesurer l'efficacité avec laquelle l'échantillonnage a permis de détecter les espèces dominantes. La courbe de raréfaction a été réalisée en utilisant une procédure de bootstraps avec 200 réplicats. Ces analyses ont été réalisées en utilisant le package iNEXT (Hsieh et al. 2014) du logiciel R 3.0.2 (R Development Core Team 2004; Fig. 4).

Les espèces dont le statut est "à confirmer» et citées dans les résultats, ne sont pas prises en compte.

L'analyse standard d'un segment de la sous-unité I du gène mitochondrial cytochrome-oxydase (COI), a été réalisée sur une sélection représentative de spécimens (299, sélection selon des critères de diversité). Les tarses médians droits (gauches, si patte absente), voire une partie du tibia pour les plus petites espèces, ont été échantillonnés à chaque spécimen. Les tissus 


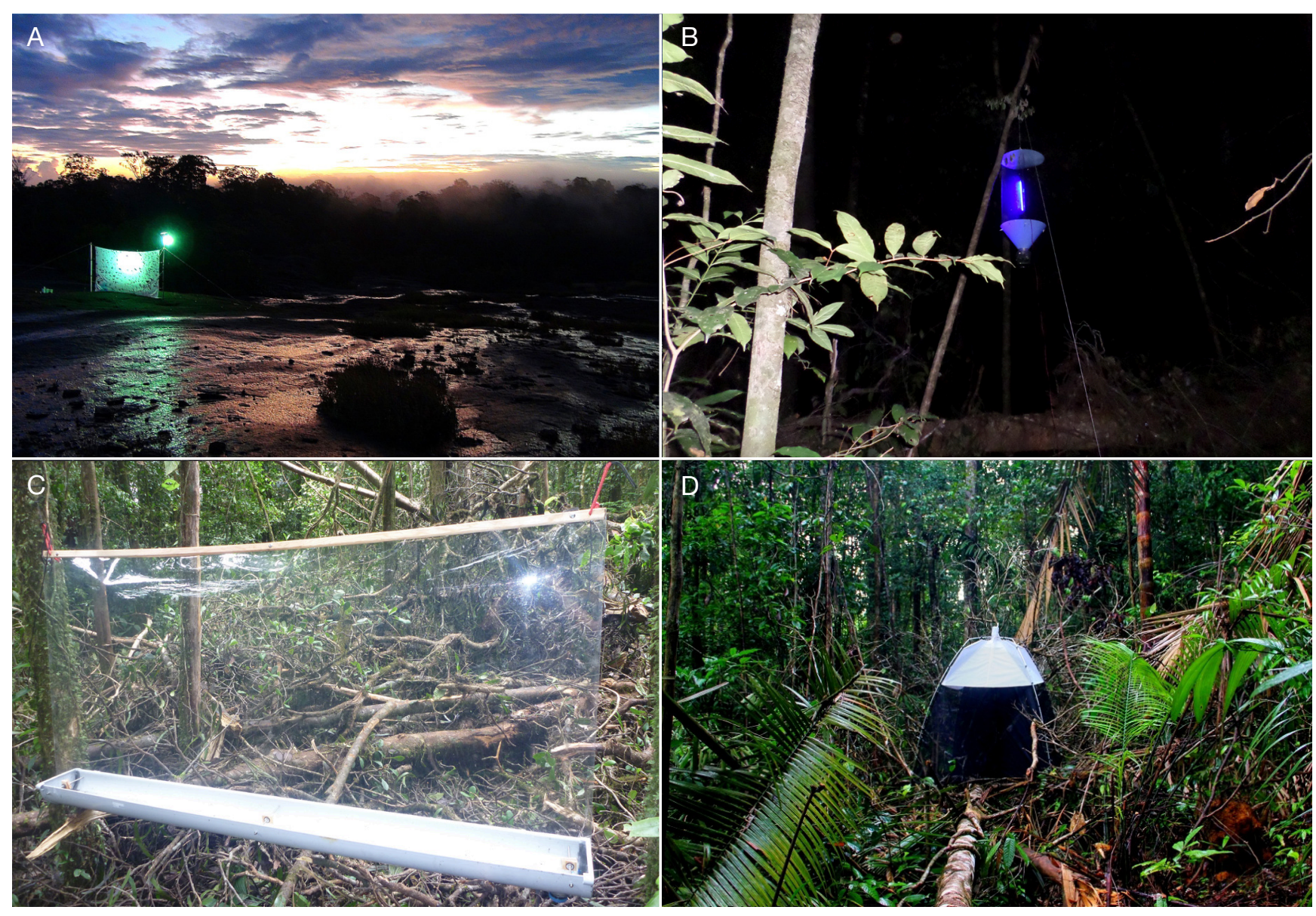

FIG. 2. - Exemples de techniques d'échantillonnage utilisées en Guyane: A, piège lumineux en présence d'entomologistes (LT); B, piège d'interception avec attraction par la lumière (ici LumiVie Bleu, PVB); C, piège vitre d'interception (FIT); $\mathbf{D}$, piège d'interception de type tente Malaise (SLAM). Crédits photos : F. Robin (A, D), J. Touroult (B) \& E. Poirier (C).

TABLEAU 1. - Liste des différentes techniques d'échantillonnage de la Société Entomologique Antilles-Guyane (SEAG), avec leurs caractéristiques.

\begin{tabular}{llll}
\hline Code & Type & Nom commun & Description \\
\hline BT & Piège à appât & Piège aérien & Bouteille avec appât (vin rouge ou banane) \\
CUV & Piège lumineux automatique & Piège lumineux & Piège Canopée à la lumière UV \\
CVB & Piège lumineux automatique & Piège lumineux & Piège Canopée lumiVie Bleue \\
CVP & Piège lumineux automatique & Piège lumineux & Piège Canopée lumiVie Rose \\
FIT & Piège d'interception & Piège à vitre & Plaque transparente surmontant une gouttière de collecte \\
HC & Chasse active & Chasse à vue & Chasse au filet ou à la main, par observation directe \\
LT & Piège lumineux & Piège lumineux (drap) & Piège lumineux alimenté par un générateur \\
MT & Piège d'interception & Malaise & Piège de toile à tendre entre des piquets ou des arbres \\
PF & Piège d'interception & Pit-Fall & Récipient planté au ras du sol \\
PGL & Piège lumineux automatique & PolyGemlight & Polytrap lumineux avec 2 LED 1W, UV + green \\
PNA & Piège lumineux automatique & Poly Néon Actinic & Polytrap lumineux avec 1 tube néon actinique 8 W \\
PSW & Piège lumineux automatique & Polyswing & Polytrap lumineux avec 4 bornes SUNNY (LED 0,4 W, 6 500 K) \\
PVB & Piège lumineux automatique & Polyvie bleu & Polytrap lumineux avec rampe LED 7,2 W, 20 000 K \\
PVP & Piège lumineux automatique & Polyvie rose & Polytrap lumineux avec rampe LED 7,2 W, 5 000 K \\
SLAM & Piège d'interception & SLAM & Sea Land and Air Malaise, Malaise autoportant \\
SPF & Piège lumineux automatique & Pit-Fall solaire & Pit-Fall surmonté d'une borne de jardin SUNNY (LED 0,4 W, 6 500 K) \\
\hline & & &
\end{tabular}

ont été envoyés au Centre canadien pour le séquençage ADN (CCDB) à l'Université de Guelph pour l'extraction de l'ADN, la réaction en chaîne de la polymérase (PCR) et le séquençage (Hajibabaei et al. 2005; Ivanova et al. 2006). La lyse tissulaire s'est produite dans $50 \mu \mathrm{L}$ de lyse tampon et de protéinase $\mathrm{K}$ $(0.02 \mathrm{mg} / \mu \mathrm{L})$ incubée à $56^{\circ} \mathrm{C}$ pendant une nuit. Un segment de 658 pb de la région 5' du gène mitochondrial COI utilisé comme le code-barre ADN standard, a été amplifié par PCR en utilisant les amorces PCR C_LepFolF / C_LepFolR (Hebert et al. 2004). Toutes les séquences ont été alignées, inspectées et arrêtées par des codons pour l'élimination des erreurs d'édition et de pseudogènes; puis chargées dans l'interface «Barcode Of 
A

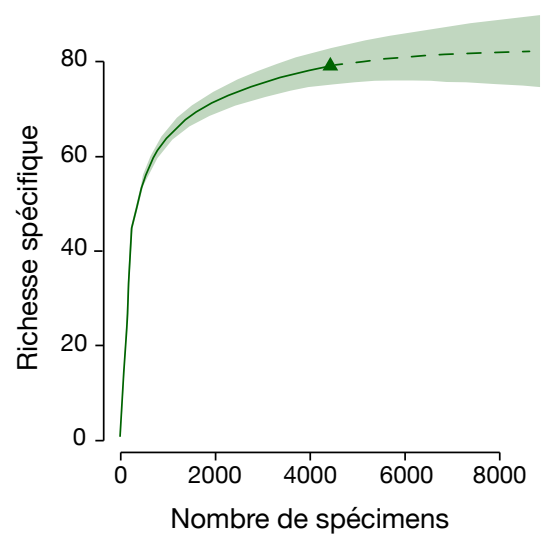

B

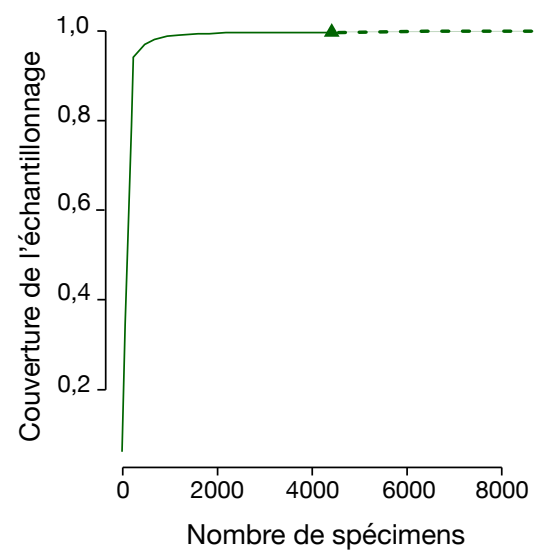

C

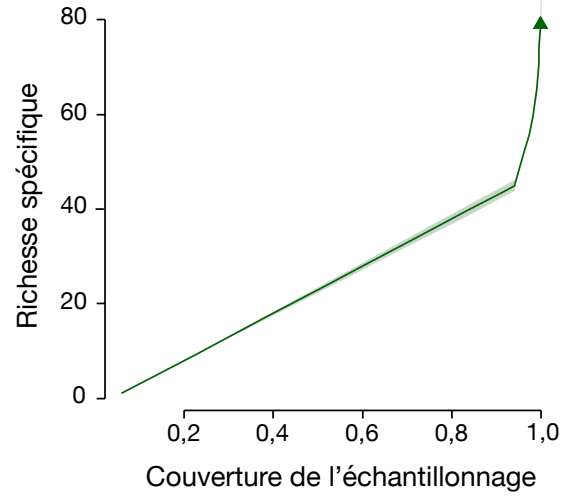

FIG. 3. - Courbes de raréfaction et d'extrapolation de la diversité spécifique des Mantodea de Guyane: A, richesse spécifique observée en fonction de l'effort d'échantillonnage (ici représenté par le nombre de spécimens figurant dans CardObs); B, couverture de l'échantillonnage en fonction de l'effort d'échantillonnage; C, richesse spécifique observée en fonction de la couverture d'échantillonnage. La courbe de raréfaction est représentée en trait continu, la courbe d'extrapolation en trait pointillé, la zone ombrée verte représente l'intervalle de confiance (95\%) basée sur une procédure de bootstrap avec 200 réplicats.

Life Data Systems» (BOLD, Biodiversity Institut of Ontario, Canada; http://www.boldsystems.org, dernière consultation le 27 novembre 2019). Les données sont actuellement gérées sous le projet: "DNA barcoding Mantodea - Collection N. Moulin" sur l'interface BOLD. Tous les enregistrements (spécimens et données des séquences) peuvent être consultés publiquement sur BOLD et GenBank, et ont été rassemblés dans le jeu de données de BOLD DS-MANGF. Les distances de Kimura-2-Parameter (K2P) ont été calculées en utilisant l'interface BOLD 4.0 (Ratnasingham \& Hebert 2007, 2013).

Les BINs ont été générés automatiquement sur BOLD à l'aide de l'analyse "Refined Single Linkage (RESL)», un algorithme en trois étapes qui incorpore toutes les séquences COI disponibles et les regroupe selon les valeurs maximales de variation intraspécifique spécifiques au niveau des ordres et des familles (Ratnasingham \& Hebert 2013).

Nous avons aligné les séquences du jeu de données à l'aide de BOLD Aligner (Amino Acid based HMM) et créé un arbre de rapprochement des séquences basé sur les distances de Kimura2-Parameter. Les divergences des séquences obtenues ont été calculées (variation intraspécifique maximale et distance génétique minimale avec l'espèce la plus proche) à l'aide de l'outil "Barcode Gap Analysis» sur BOLD (Puillandre et al. 2012).

Ensuite, nous avons appliqué l'analyse «BIN Discordance» disponible sur BOLD afin de révéler les groupements d'espèces ayant des BINs discordant ou des BINS partagés.

\section{RÉSULTATS}

\section{RÉSULTATS GLOBAUX}

Le recensement des Mantes de Guyane conservées au MNHN, dans la collection privée du premier auteur et à partir des observations d'entomologistes, a permis d'accumuler 4424 données, soit 90 espèces connues en Guyane (Tableau 2). Grâce à cette synthèse, neuf espèces sont citées pour la première fois en Guyane: Chaeteessa filata Burmeister, 1838, Chopardiella poulaini Lombardo \& Agabiti, 2001, Liturgusa tessae Svenson, 2014, Metilia integra Stål, 1877, Parastagmatoptera unipunctata (Burmeister, 1838), Pseudovates brevicornis (Stål, 1877), Pseudovates cingulata (Drury, 1773), Stagmatoptera binotata Scudder, 1869, Stagmatoptera biocellata Saussure, 1869.

À l'inverse, cette synthèse a permis de rétablir l'état des connaissances sur la répartition de plusieurs espèces, citées de façon erronée de Guyane par Agudelo Rondon et al. (2007) : Mantoida fulgidipennis Westwood, 1889 a été mise en synonymie avec Mantoida brunneriana (Saussure, 1871), en Guyane (La Greca \& Lombardo 1989) et ne peut être considérée, actuellement, comme une espèce distincte présente sur le Département.

Acontista chopardi Giglio-Tos, 1927 n'est autre que le mâle d'Acontista gracilis Chopard, 1912. Depuis la séparation des individus décrits par Chopard en Acontista cordillerae Saussure, 1869, pour les femelles et en Acontista chopardi pour le mâle, par Giglio-Tos en 1927, cette confusion a été maintenue par les auteurs successifs qui ont disserté sur l'entomofaune de Guyane. Des récoltes ultérieures ont fourni un plus grand nombre de spécimens des deux sexes dont un couple in copula qui a prouvé que Chopard avait raison (Roy 2006a). Acontista concinna (Perty, 1833) est citée de nombreuses fois de Guyane par différents auteurs (Terra 1995; Agudelo Rondon et al. 2007). Cependant, originaire du Brésil, elle n'a jamais été collectée de nouveau.

Hagiomantis surinamensis (Saussure, 1872) est citée, par erreur, de Guyane (Ehrmann 2002; Agudelo Rondon et al. 2007) alors que le dernier auteur à la citer avant les années 2000 (Jantsch 1999), ne la considère pas présente en Guyane. Le formidable travail de révision du genre Liturgusa par Svenson (2014) a permis d'éclaircir la situation taxonomique de cet ensemble d'espèces de Mantes dont l'identification morphologique est difficile. Ainsi, Liturgusa annulipes (Audinet-Serville, 1838) n'est plus à considérer comme présente en Guyane. Plusieurs spécimens considérés comme L. annulipes ont été les supports de descriptions de nouvelles espèces comme Liturgusa milleri Svenson, 2014 et Liturgusa maroni Svenson, 2014 , effectivement présentes en Guyane, de façon très sporadique. 
TABLEAU 2. - Liste des espèces de Mantodea présentes en Guyane avec le nombre de données enregistrées sous CardObs, des données de synonymies, la répartition néotropicale et les dernières publications de référence. Abréviations: ar, Argentine; be, Belize; bo, Bolivie; br, Brésil; ch, Chili; co, Colombie; cr, Costa Rica; cu, Cuba; ec, Équateur; gf, Guyane; gu, Guatemala; gy, Guyana; ho, Honduras; ht, Haïti ; ja, Jamaïque; me, Mexique; ni, Nicaragua; pe, Pérou; pn, Panama; py, Paraguay; su, Suriname; tt, Trinidad \& Tobago; ur, Uruguay; us, États-Unis; vn, Vénézuela.

\begin{tabular}{|c|c|c|c|c|c|c|}
\hline Famille & Sous-famille & Espèce & $\begin{array}{l}\text { Données } \\
\text { CardObs }\end{array}$ & Commentaires & $\begin{array}{l}\text { Distribution } \\
\text { néotropicale }\end{array}$ & Références \\
\hline \multirow{2}{*}{$\begin{array}{l}\text { Chaeteessidae } \\
\text { Handlirsch, } \\
1925\end{array}$} & \multirow{2}{*}{ Chaeteessinae } & $\begin{array}{l}\text { Chaeteessa filata } \\
\text { Burmeister, } 1838\end{array}$ & 2 & - & br gf su & $\begin{array}{l}\text { Agudelo Rondon } \\
\text { et al. } 2007\end{array}$ \\
\hline & & $\begin{array}{l}\text { Chaeteessa valida } \\
\text { (Perty, 1833) }\end{array}$ & 11 & Hoplophora valida Perty, 1833 & br co gf & $\begin{array}{l}\text { Agudelo Rondon } \\
\text { et al. } 2007\end{array}$ \\
\hline \multirow[t]{2}{*}{$\begin{array}{l}\text { Mantoididae } \\
\text { Giglio-Tos, } \\
1919\end{array}$} & \multirow[t]{2}{*}{ Mantoidinae } & $\begin{array}{l}\text { Mantoida } \\
\quad \text { brunneriana } \\
\text { (Saussure, 1871) }\end{array}$ & 301 & $\begin{array}{l}\text { Chaeteessa brunneriana Saussure } 1871 \\
\text { Syn. Mantoida fulgidipennis Westwood } 1889\end{array}$ & $\begin{array}{l}\text { bo br co ec } \\
\text { gf pn py }\end{array}$ & $\begin{array}{l}\text { Agudelo Rondon } \\
\text { et al. } 2007 \text {; } \\
\text { Roy } 2019\end{array}$ \\
\hline & & $\begin{array}{l}\text { Vespamantoida } \\
\text { toulgoeti } \\
\text { (Roy, 2010) }\end{array}$ & 8 & - & gf & $\begin{array}{l}\text { Roy 2010, 2019; } \\
\quad \text { Svenson \& } \\
\text { Rodrigues } 2019\end{array}$ \\
\hline \multirow[t]{12}{*}{$\begin{array}{l}\text { Thespidae } \\
\text { Saussure, } \\
1869\end{array}$} & \multirow[t]{2}{*}{$\begin{array}{l}\text { Pseudomiopteryginae } \\
\text { Giglio-Tos, } 1917\end{array}$} & $\begin{array}{l}\text { Pseudomiopteryx } \\
\text { guyanensis } \\
\text { Chopard, } 1912\end{array}$ & 75 & $\begin{array}{l}\text { Syn. ? Pseudomiopteryx spinifrons } \\
\text { Saussure, } 1870\end{array}$ & $\begin{array}{l}\text { br gf pe } \\
\text { su vn }\end{array}$ & $\begin{array}{l}\text { Agudelo Rondon } \\
\text { et al. } 2007 \text {; } \\
\text { Roy } 2019\end{array}$ \\
\hline & & $\begin{array}{l}\text { Promiopteryx } \\
\text { granadensis } \\
\text { (Saussure, 1870) }\end{array}$ & 0 & Miopteryx granadensis Saussure, 1870 & br co gf gy tt & $\begin{array}{l}\text { Agudelo Rondon } \\
\text { et al. } 2007\end{array}$ \\
\hline & \multirow[t]{2}{*}{$\begin{array}{l}\text { Bantiinae Rivera \& } \\
\text { Svenson, } 2016\end{array}$} & $\begin{array}{l}\text { Bantia fusca } \\
\quad \text { Chopard, } 1912\end{array}$ & 54 & - & br gf & $\begin{array}{l}\text { Agudelo Rondon } \\
\text { et al. } 2007 ; \\
\text { Roy } 2019\end{array}$ \\
\hline & & $\begin{array}{l}\text { Bantiella fusca } \\
\quad \text { Giglio-Tos, } 1915\end{array}$ & 0 & - & gf tt & $\begin{array}{l}\text { Agudelo Rondon } \\
\text { et al. } 2007\end{array}$ \\
\hline & $\begin{array}{l}\text { Musoniellinae } \\
\text { Rivera \& Svenson, } \\
2016\end{array}$ & $\begin{array}{l}\text { Leptomiopteryx } \\
\text { dispar Chopard, } \\
1912\end{array}$ & 18 & Syn. Navimons amapaensis Piza, 1970 & br gf & $\begin{array}{l}\text { Terra 1995; } \\
\quad \text { Agudelo } \\
\text { Rondon et al. } \\
2007\end{array}$ \\
\hline & \multirow[t]{7}{*}{$\begin{array}{l}\text { Thespinae } \\
\text { Saussure, } 1869\end{array}$} & $\begin{array}{l}\text { Macromusonia } \\
\text { conspersa } \\
\text { (Saussure, 1870) }\end{array}$ & 3 & $\begin{array}{l}\text { Thespis conspersa Saussure, } 1870 \\
\text { Catamusonia conspersa - Giglio-Tos, } 1927\end{array}$ & $\begin{array}{l}\text { bo br co ec } \\
\text { gf gy pe }\end{array}$ & $\begin{array}{l}\text { Agudelo Rondon } \\
\text { et al. } 2007\end{array}$ \\
\hline & & $\begin{array}{l}\text { Macromusonia } \\
\text { major } \\
\text { (Saussure \& } \\
\text { Zehntner, 1894) }\end{array}$ & 59 & $\begin{array}{l}\text { Musonia major Saussure \& Zehntner, } 1894 \\
\text { Catamusonia major - Giglio-Tos, } 1927\end{array}$ & $\begin{array}{l}\text { br co ec gf } \\
\text { pe su vn }\end{array}$ & $\begin{array}{l}\text { Agudelo Rondon } \\
\text { et al. } 2007\end{array}$ \\
\hline & & $\begin{array}{l}\text { Musonia } \\
\text { fuscescens } \\
\text { (Chopard, 1912) }\end{array}$ & 6 & Mionyx fuscescens Chopard, 1912 & gf & Ehrmann 2002 \\
\hline & & $\begin{array}{l}\text { Musonia lineata } \\
\quad \text { (Chopard, 1912) }\end{array}$ & 1 & Mionyx lineatus Chopard, 1912 & gf & $\begin{array}{l}\text { Agudelo Rondon } \\
\text { et al. } 2007\end{array}$ \\
\hline & & $\begin{array}{l}\text { Musonia surinama } \\
\quad \text { (Saussure, 1869) }\end{array}$ & 109 & $\begin{array}{l}\text { Thespis surinama Saussure, } 1869 \\
\text { Mionyx surinama - Kirby, } 1904 \\
\text { Syn. Musonia femorata Saussure \& } \\
\text { Zehntner, } 1894\end{array}$ & $\begin{array}{l}\text { co gf gy ni pn } \\
\text { sutt vn }\end{array}$ & $\begin{array}{l}\text { Agudelo Rondon } \\
\text { et al. } 2007 \text {; } \\
\text { Roy } 2019\end{array}$ \\
\hline & & $\begin{array}{l}\text { Pseudomusonia } \\
\text { maculosa } \\
\text { (Chopard, 1912) }\end{array}$ & 12 & $\begin{array}{l}\text { Myonix maculosus Chopard, } 1912 \\
\text { Eumionyx maculosus - Giglio-Tos, } 1927\end{array}$ & gf & $\begin{array}{l}\text { Agudelo Rondon } \\
\text { et al. } 2007 \text {; } \\
\text { Roy } 2019\end{array}$ \\
\hline & & $\begin{array}{l}\text { Thesprotia filum } \\
\text { (Lichtenstein, } \\
\text { 1796) }\end{array}$ & 2 & $\begin{array}{l}\text { Mantis filum Lichtenstein, } 1796 \\
\text { Oligonyx filum - Saussure, } 1869 \\
\text { Spanionyx filum - Kirby, } 1904\end{array}$ & br gf su tt & $\begin{array}{l}\text { Agudelo Rondon } \\
\text { et al. } 2007 \text {; } \\
\text { Roy } 2019\end{array}$ \\
\hline \multirow[t]{7}{*}{$\begin{array}{l}\text { Angelidae } \\
\quad \text { Beier, } 1935\end{array}$} & & $\begin{array}{l}\text { Angela armata } \\
\quad \text { (De Haan, 1842) }\end{array}$ & 13 & $\begin{array}{l}\text { Mantis (Thespis) armata De Haan, } 1842 \\
\text { Phasmomantis armata - Saussure, } 1871 \\
\text { Rivetina armata - Saussure, } 1872 \\
\text { Syn. Thespis fulgida Saussure, } 1872 \\
\text { Angela fulgida (Saussure, 1872) }\end{array}$ & $\begin{array}{l}\text { br co cr ec } \\
\text { gf pe }\end{array}$ & $\begin{array}{l}\text { Agudelo Rondon } \\
\text { et al. } 2007\end{array}$ \\
\hline & & $\begin{array}{l}\text { Angela guianensis } \\
\quad \text { Rehn, } 1906\end{array}$ & 174 & Syn. Thespis infuscata Chopard, 1912 & $\begin{array}{l}\text { bo br co cr } \\
\text { gy gf su vn }\end{array}$ & $\begin{array}{l}\text { Agudelo Rondon } \\
\text { et al. } 2007 \text {; } \\
\text { Roy } 2019\end{array}$ \\
\hline & & $\begin{array}{l}\text { Angela lemoulti } \\
\text { (Chopard, 1910) }\end{array}$ & 10 & Thespis lemoulti Chopard, 1910 & br gf vn & $\begin{array}{l}\text { Agudelo Rondon } \\
\text { et al. } 2007\end{array}$ \\
\hline & & $\begin{array}{l}\text { Angela maxima } \\
\quad(\text { Chopard, 1910) }\end{array}$ & 4 & Thespis maxima Chopard, 1910 & gf & $\begin{array}{l}\text { Agudelo Rondon } \\
\text { et al. } 2007\end{array}$ \\
\hline & & $\begin{array}{l}\text { Angela } \\
\text { purpurascens } \\
\text { (Olivier, 1792) }\end{array}$ & 12 & $\begin{array}{l}\text { Mantis purpurascens Olivier, } 1792 \\
\text { Thespis purpurascens - Audinet-Serville, } \\
\quad 1831 \\
\text { Syn. Mantis versicolor Saussure, } 1871\end{array}$ & br gf pe su & $\begin{array}{l}\text { Agudelo Rondon } \\
\text { et al. } 2007\end{array}$ \\
\hline & & $\begin{array}{l}\text { Angela } \\
\quad \text { quinquemaculata } \\
\text { (Olivier, 1792) }\end{array}$ & 0 & $\begin{array}{l}\text { Mantis quinquemaculata Olivier, } 1792 \\
\text { Thespis quinquemaculata - Kirby, } 1904 \\
\text { Syn. Mantis picta - Lichtenstein, } 1802\end{array}$ & br gf su tt vn & $\begin{array}{l}\text { Agudelo Rondon } \\
\text { et al. } 2007\end{array}$ \\
\hline & & $\begin{array}{l}\text { Angela saussurii } \\
\text { Giglio-Tos, } 1927\end{array}$ & 21 & - & br gf su vn & $\begin{array}{l}\text { Agudelo Rondon } \\
\text { et al. } 2007\end{array}$ \\
\hline
\end{tabular}


TABLEAU 2. - Suite.

\begin{tabular}{|c|c|c|c|c|c|c|}
\hline Famille & Sous-famille & Espèce & $\begin{array}{l}\text { Données } \\
\text { CardObs }\end{array}$ & Commentaires & $\begin{array}{l}\text { Distribution } \\
\text { néotropicale }\end{array}$ & Références \\
\hline \multirow[t]{6}{*}{$\begin{array}{l}\text { Liturgusidae } \\
\text { Giglio-Tos, } \\
1919\end{array}$} & \multirow[t]{6}{*}{$\begin{array}{l}\text { Liturgusinae } \\
\text { Giglio-Tos, } 1919\end{array}$} & $\begin{array}{l}\text { Hagiomantis } \\
\text { mesopoda } \\
\text { (Westwood, } \\
\text { 1889) }\end{array}$ & 7 & $\begin{array}{l}\text { Liturgousa mesopoda Westwood, } 1889 \\
\text { Liturgusa mesopoda - Beier, } 1935\end{array}$ & br co gf & $\begin{array}{l}\text { Chopard 1912; } \\
\text { Terra 1995; } \\
\text { Agudelo } \\
\text { Rondon et al. } \\
2007\end{array}$ \\
\hline & & $\begin{array}{l}\text { Hagiomantis ornata } \\
\text { (Stoll, 1813) }\end{array}$ & 8 & $\begin{array}{l}\text { Mantis ornata Stoll, } 1813 \\
\text { Syn. Mantis lutescens (Guérin-Méneville \& } \\
\text { Percheron, 1835) }\end{array}$ & bo br gf su & $\begin{array}{l}\text { Agudelo Rondon } \\
\text { et al. } 2007\end{array}$ \\
\hline & & $\begin{array}{l}\text { Liturgusa } \\
\text { cayennensis } \\
\text { (Saussure, 1869) }\end{array}$ & 34 & Liturgousa cayennensis Saussure, 1869 & $\begin{array}{l}\text { br co gf gu } \\
\text { me pn tt vn }\end{array}$ & Svenson 2014 \\
\hline & & $\begin{array}{l}\text { Liturgusa maroni } \\
\text { Svenson, } 2014\end{array}$ & 5 & - & gf & $\begin{array}{l}\text { Svenson 2014; } \\
\quad \text { Roy } 2019\end{array}$ \\
\hline & & $\begin{array}{l}\text { Liturgusa milleri } \\
\text { Svenson, } 2014\end{array}$ & 19 & - & br gf su & $\begin{array}{l}\text { Svenson 2014; } \\
\text { Roy } 2019\end{array}$ \\
\hline & & $\begin{array}{l}\text { Liturgusa tessae } \\
\text { Svenson, } 2014\end{array}$ & 1 & - & $\begin{array}{l}\text { bo br gf } \\
\text { gu pe }\end{array}$ & Svenson 2014 \\
\hline \multirow[t]{12}{*}{$\begin{array}{l}\text { Photinaidae } \\
\text { Giglio-Tos, } \\
1915\end{array}$} & \multirow[t]{3}{*}{$\begin{array}{l}\text { Macromantinae } \\
\text { Brunner de } \\
\text { Wattenwyl, } 1893\end{array}$} & $\begin{array}{l}\text { Macromantis } \\
\text { hyalina } \\
\text { (De Geer, 1773) }\end{array}$ & 13 & Mantis hyalina De Geer, 1773 & $\begin{array}{l}\text { be br co cr } \\
\text { ec gf ni pn } \\
\text { pe su vn }\end{array}$ & $\begin{array}{l}\text { Agudelo Rondon } \\
\text { et al. } 2007\end{array}$ \\
\hline & & $\begin{array}{l}\text { Macromantis } \\
\text { ovalifolia } \\
\text { (Stoll, 1813) }\end{array}$ & 42 & Mantis ovalifolia Stoll, 1813 & $\begin{array}{l}\text { br gf gy pn } \\
\text { pe su }\end{array}$ & $\begin{array}{l}\text { Agudelo Rondon } \\
\text { et al. 2007; } \\
\text { Roy } 2019\end{array}$ \\
\hline & & $\begin{array}{l}\text { Macromantis } \\
\text { saussurei } \\
\text { Roy, } 2002\end{array}$ & 7 & - & bo gf su vn & $\begin{array}{l}\text { Agudelo Rondon } \\
\text { et al. } 2007 \text {; } \\
\text { Roy } 2019\end{array}$ \\
\hline & \multirow[t]{2}{*}{$\begin{array}{l}\text { Cardiopterinae } \\
\text { Rehn, } 1911\end{array}$} & $\begin{array}{l}\text { Cardioptera } \\
\text { nigridens } \\
\text { Werner, } 1925\end{array}$ & 0 & - & br co gf & $\begin{array}{l}\text { Agudelo Rondon } \\
\text { et al. } 2007\end{array}$ \\
\hline & & $\begin{array}{l}\text { Cardioptera } \\
\text { squalodon } \\
\text { Werner, } 1932\end{array}$ & 70 & & br gf su & $\begin{array}{l}\text { Agudelo Rondon } \\
\text { et al. } 2007\end{array}$ \\
\hline & \multirow[t]{7}{*}{$\begin{array}{l}\text { Photinainae } \\
\text { Giglio-Tos, } 1915\end{array}$} & $\begin{array}{l}\text { Metriomantis ovata } \\
\text { Saussure \& } \\
\text { Zehntner, } 1894\end{array}$ & 2 & - & br co gf vn & $\begin{array}{l}\text { Agudelo Rondon } \\
\text { et al. } 2007\end{array}$ \\
\hline & & $\begin{array}{l}\text { Metriomantis pilosa } \\
\text { (Chopard, 1912) }\end{array}$ & 88 & Photina pilosa Chopard, 1912 & $\operatorname{cog} g$ & Roy 2006b, 2019 \\
\hline & & $\begin{array}{l}\text { Metriomantis } \\
\text { pilosella Giglio- } \\
\text { Tos, } 1915\end{array}$ & 159 & Syn. ? Photina vitrea (Burmeister, 1838) & br gf vn & $\begin{array}{l}\text { Agudelo Rondon } \\
\text { et al. 2007; } \\
\text { Roy } 2019\end{array}$ \\
\hline & & $\begin{array}{l}\text { Microphotina } \\
\text { viridescens } \\
\text { (Chopard, 1912) }\end{array}$ & 182 & Photina viridescens Chopard, 1912 & gf & $\begin{array}{l}\text { François \& Roy } \\
2015\end{array}$ \\
\hline & & $\begin{array}{l}\text { Microphotina } \\
\text { vitripennis } \\
\text { (Saussure, 1872) }\end{array}$ & 53 & $\begin{array}{l}\text { Cardioptera vitripennis Saussure, } 1872 \\
\text { Photina vitripennis - Kirby, } 1904 \\
\text { Hicetia vitripennis - Giglio-Tos, } 1927\end{array}$ & br gf vn & $\begin{array}{l}\text { Agudelo Rondon } \\
\text { et al. } 2007\end{array}$ \\
\hline & & $\begin{array}{l}\text { Microphotina } \\
\text { viridula } \\
\text { Roy, } 2019\end{array}$ & 16 & & gf & Roy 2019 \\
\hline & & $\begin{array}{l}\text { Photina } \\
\text { amplipennis } \\
\text { Stål, } 1877\end{array}$ & 0 & $\begin{array}{l}\text { Syn. Mantis (Photina) vitrea Burmeister, } 1838 \\
\text { Syn. Cardioptera vitrea - Saussure, } 1870\end{array}$ & bo br gf vn & $\begin{array}{l}\text { Agudelo Rondon } \\
\text { et al. 2007; } \\
\text { Svenson \& } \\
\text { Branham } 2007\end{array}$ \\
\hline \multirow[t]{6}{*}{$\begin{array}{l}\text { Acanthopidae } \\
\text { Burmeister, } \\
1838\end{array}$} & \multirow[t]{6}{*}{$\begin{array}{l}\text { Acanthopinae } \\
\text { Burmeister, } 1838\end{array}$} & $\begin{array}{l}\text { Acanthops } \\
\text { fuscifolia } \\
\text { (Olivier, 1792) }\end{array}$ & 60 & - & gf gy & $\begin{array}{l}\text { Agudelo Rondon } \\
\text { et al. 2007; } \\
\text { Roy } 2019\end{array}$ \\
\hline & & $\begin{array}{l}\text { Acanthops erosa } \\
\text { Audinet- } \\
\text { Serville, } 1838\end{array}$ & 2 & - & br gf & $\begin{array}{l}\text { Agudelo Rondon } \\
\text { et al. } 2007\end{array}$ \\
\hline & & $\begin{array}{l}\text { Acanthops soukana } \\
\text { Roy, } 2002\end{array}$ & 2 & - & gf & $\begin{array}{l}\text { Agudelo Rondon } \\
\text { et al. } 2007\end{array}$ \\
\hline & & $\begin{array}{l}\text { Plesiacanthops } \\
\text { tuberculata } \\
\text { (Saussure, 1870) }\end{array}$ & 36 & Acanthops tuberculatus Saussure, 1870 & br co gf gy & $\begin{array}{l}\text { Agudelo Rondon } \\
\text { et al. 2007; } \\
\text { Roy } 2019\end{array}$ \\
\hline & & $\begin{array}{l}\text { Lagrecacanthops } \\
\text { guyanensis } \\
\text { Roy, } 2004\end{array}$ & 2 & - & gf & $\begin{array}{l}\text { Agudelo Rondon } \\
\text { et al. 2007; } \\
\text { Roy } 2019\end{array}$ \\
\hline & & $\begin{array}{l}\text { Metacanthops } \\
\text { amazonica } \\
\text { (Beier, 1930) }\end{array}$ & 35 & $\begin{array}{l}\text { Acanthops amazonica Beier, } 1930 \\
\text { Metilia amazonica - Roy, } 2002\end{array}$ & br gf & $\begin{array}{l}\text { Roy 2002a, } \\
\text { 2019; Agudelo } \\
\text { Rondon et al. } \\
2007,2019\end{array}$ \\
\hline
\end{tabular}


TABleAu 2. - Suite.

\begin{tabular}{|c|c|c|c|c|c|c|}
\hline \multirow[t]{2}{*}{ Famille } & \multirow[t]{2}{*}{ Sous-famille } & Espèce & $\begin{array}{l}\text { Données } \\
\text { CardObs }\end{array}$ & Commentaires & \multicolumn{2}{|c|}{$\begin{array}{l}\text { Distribution Références } \\
\text { néotropicale }\end{array}$} \\
\hline & & $\begin{array}{l}\text { Metilia brunnerii } \\
\quad \text { (Saussure, 1871) }\end{array}$ & 19 & $\begin{array}{l}\text { Acanthops brunnerii Saussure, } 1871 \\
\text { Syn. Metilia adusta Gerstaecker, } 1889\end{array}$ & $\begin{array}{l}\text { bo br cr co } \\
\text { gf ni pe su vn }\end{array}$ & $\begin{array}{l}\text { Agudelo Rondon } \\
\text { et al. 2007; } \\
\text { Roy } 2019\end{array}$ \\
\hline & & $\begin{array}{l}\text { Metilia integra } \\
\text { Stål, } 1877\end{array}$ & 2 & - & ec gf & Giglio-Tos 1927 \\
\hline & & $\begin{array}{l}\text { Pseudacanthops } \\
\text { spinulosa } \\
\text { (Saussure, 1870) }\end{array}$ & 38 & Paracanthops spinulosa Saussure, 1870 & $\begin{array}{l}\text { bo br co ec } \\
\text { gf gy }\end{array}$ & $\begin{array}{l}\text { Agudelo Rondon } \\
\text { et al. } 2007 \text {; } \\
\text { Roy } 2019\end{array}$ \\
\hline & $\begin{array}{l}\text { Stenophyllinae } \\
\text { Saussure, } 1869\end{array}$ & $\begin{array}{l}\text { Stenophylla gallardi } \\
\text { Roy, } 2005\end{array}$ & 8 & - & gf & $\begin{array}{l}\text { Agudelo Rondon } \\
\text { et al. } 2007\end{array}$ \\
\hline & & $\begin{array}{l}\text { Acontista concinna } \\
\text { (Perty, 1832) }\end{array}$ & 0 & Mantis concinna Perty, 1832 & $\begin{array}{l}\text { ar bo br co } \\
\text { ec gf pe py }\end{array}$ & $\begin{array}{l}\text { Agudelo Rondon } \\
\text { et al. } 2007\end{array}$ \\
\hline & & $\begin{array}{l}\text { Acontista } \\
\text { cayennensis } \\
\text { Saussure \& } \\
\text { Zehntner, } 1894\end{array}$ & 1 & - & brgf & $\begin{array}{l}\text { Agudelo Rondon } \\
\text { et al. } 2007\end{array}$ \\
\hline & & $\begin{array}{l}\text { Acontista } \\
\text { maroniensis } \\
\text { Chopard, } 1912\end{array}$ & 14 & & br gf & $\begin{array}{l}\text { Agudelo Rondon } \\
\text { et al. } 2007\end{array}$ \\
\hline & & $\begin{array}{l}\text { Acontista gracilis } \\
\text { Chopard, } 1912\end{array}$ & 68 & Syn. Acontista chopardi Giglio-Tos, 1927 & gf & $\begin{array}{l}\text { Agudelo Rondon } \\
\text { et al. 2007; } \\
\text { Roy } 2019\end{array}$ \\
\hline & & $\begin{array}{l}\text { Callibia diana } \\
\quad \text { (Stoll, 1813) }\end{array}$ & 15 & - & $\begin{array}{l}\text { bo br co gf } \\
\text { pe vn }\end{array}$ & $\begin{array}{l}\text { Agudelo Rondon } \\
\text { et al. } 2007\end{array}$ \\
\hline & & $\begin{array}{l}\text { Ovalimantis } \\
\text { maculata } \\
\text { Roy, } 2015\end{array}$ & 1 & - & gf & Roy 2015 \\
\hline & & $\begin{array}{l}\text { Paratithrone royi } \\
\text { Lombardo, } 1996\end{array}$ & 7 & - & br gf & $\begin{array}{l}\text { Agudelo Rondon } \\
\text { et al. } 2007 \text {; } \\
\text { Roy } 2019\end{array}$ \\
\hline & & $\begin{array}{l}\text { Raptrix perspicua } \\
\text { (Fabricius, 1787) }\end{array}$ & 677 & - & $\begin{array}{l}\text { br co gf } \\
\text { su vn }\end{array}$ & $\begin{array}{l}\text { Agudelo Rondon } \\
\text { et al. } 2007 \text {; } \\
\text { Roy } 2019\end{array}$ \\
\hline & & $\begin{array}{l}\text { Tithrone } \\
\quad \text { roseipennis } \\
\text { (Saussure, 1870) }\end{array}$ & 20 & $\begin{array}{l}\text { Acontista roseipennis Saussure, } 1870 \\
\text { Syn. Tithrone trinitatis Giglio-Tos, } 1927\end{array}$ & $\begin{array}{l}\text { br co cr gf } \\
\text { tt us vn }\end{array}$ & $\begin{array}{l}\text { Agudelo Rondon } \\
\text { et al. } 2007 \text {; } \\
\text { Roy } 2019\end{array}$ \\
\hline \multirow[t]{8}{*}{$\begin{array}{l}\text { Mantidae } \\
\text { Latreille, } \\
1802\end{array}$} & \multirow[t]{2}{*}{$\begin{array}{l}\text { Choeradodinae } \\
\text { Saussure, } 1869\end{array}$} & $\begin{array}{l}\text { Choeradodis } \\
\text { rhomboidea } \\
\text { (Stoll, 1813) }\end{array}$ & 38 & $\begin{array}{l}\text { Mantis rhomboidea Stoll, } 1813 \\
\text { Syn. Choeradodis hyalina Audinet- } \\
\text { Serville, } 1831 \\
\text { Syn. Choeradodis laticollis Audinet- } \\
\text { Serville, } 1831\end{array}$ & $\begin{array}{l}\text { bo br co cr } \\
\text { ec gf gy me } \\
\text { pe su vn }\end{array}$ & $\begin{array}{l}\text { Agudelo Rondon } \\
\text { et al. 2007; } \\
\text { Roy } 2019\end{array}$ \\
\hline & & $\begin{array}{l}\text { Choeradodis } \\
\text { strumaria } \\
\text { (Linnaeus, 1758) }\end{array}$ & 16 & $\begin{array}{l}\text { Gryllus (Mantis) strumarius Linnaeus, } 1758 \\
\text { Mantis strumaria - Linnaeus, } 1767 \\
\text { Syn. Choeradodis cancellata Fabricius, } 1775 \\
\text { Syn. Mantis (Craurusa) cancellata } \\
\text { Burmeister, } 1838\end{array}$ & $\begin{array}{l}\text { co gf gy } \\
\text { pe su }\end{array}$ & $\begin{array}{l}\text { Agudelo Rondon } \\
\text { et al. 2007; } \\
\text { Roy } 2019\end{array}$ \\
\hline & \multirow[t]{6}{*}{$\begin{array}{l}\text { Vatinae } \\
\text { Stål, } 1877\end{array}$} & $\begin{array}{l}\text { Oxyopsis rubicunda } \\
\text { (Stoll, 1813) }\end{array}$ & 115 & $\begin{array}{l}\text { Mantis rubicunda Stoll, } 1813 \\
\text { Oxyops rubicunda - Saussure, } 1871\end{array}$ & $\begin{array}{l}\text { br ch co gf } \\
\text { su tt ur vn }\end{array}$ & $\begin{array}{l}\text { Agudelo Rondon } \\
\text { et al. } 2007\end{array}$ \\
\hline & & $\begin{array}{l}\text { Oxyopsis saussurei } \\
\text { Giglio-Tos, } 1914\end{array}$ & 35 & - & br gf su tt & $\begin{array}{l}\text { Agudelo Rondon } \\
\text { et al. 2007; } \\
\text { Roy } 2019\end{array}$ \\
\hline & & $\begin{array}{l}\text { Parastagmatoptera } \\
\text { flavoguttata } \\
\text { (Audinet-Serville, } \\
\text { 1838) }\end{array}$ & 482 & $\begin{array}{l}\text { Mantis flavoguttata Audinet-Serville, } 1838 \\
\text { Stagmatoptera flavoguttata - Saussure, } 1869 \\
\text { Syn. Parastagmatoptera abnormis Beier, } 1963 \\
\text { Syn. Stagmomantis hoorie Caudell, } 1910 \\
\text { Syn. Parastagmatoptera hoorie } \\
\quad \text { (Caudell, 1910) } \\
\text { Syn. Parastagmatoptera tessellata } \\
\text { Saussure \& Zehntner, } 1894\end{array}$ & $\begin{array}{l}\text { br co cr ec } \\
\text { gf vn }\end{array}$ & $\begin{array}{l}\text { Agudelo Rondon } \\
\text { et al. } 2007 \text {; } \\
\text { Roy } 2019\end{array}$ \\
\hline & & $\begin{array}{l}\text { Parastagmatoptera } \\
\text { immaculata } \\
\text { Chopard, } 1912\end{array}$ & 249 & $\begin{array}{l}\text { Citée comme variation de Parastagmatoptera } \\
\text { flavoguttata (Audinet-Serville, 1838) }\end{array}$ & gf & Chopard 1912 \\
\hline & & $\begin{array}{l}\text { Parastagmatoptera } \\
\text { unipunctata } \\
\text { (Burmeister, } \\
\text { 1838) }\end{array}$ & 7 & $\begin{array}{l}\text { Mantis unipunctata Burmeister, } 1838 \\
\text { Syn. Parastagmatoptera serricornis } \\
\text { Kirby, } 1904 \\
\text { Syn. Parastagmatoptera vitrepennis } \\
\text { Bruner, } 1906\end{array}$ & $\begin{array}{l}\text { ar br co gf } \\
\text { py su vn }\end{array}$ & $\begin{array}{l}\text { Agudelo Rondon } \\
\text { et al. } 2007\end{array}$ \\
\hline & & $\begin{array}{l}\text { Pseudoxyops } \\
\text { perpulchra } \\
\text { (Westwood, } \\
\text { 1889) }\end{array}$ & 1 & Stagmatoptera perpulchra Westwood, 1889 & br co gf us & $\begin{array}{l}\text { Agudelo Rondon } \\
\text { et al. 2007; } \\
\text { Roy } 2019\end{array}$ \\
\hline
\end{tabular}


TABleAu 2. - Suite.

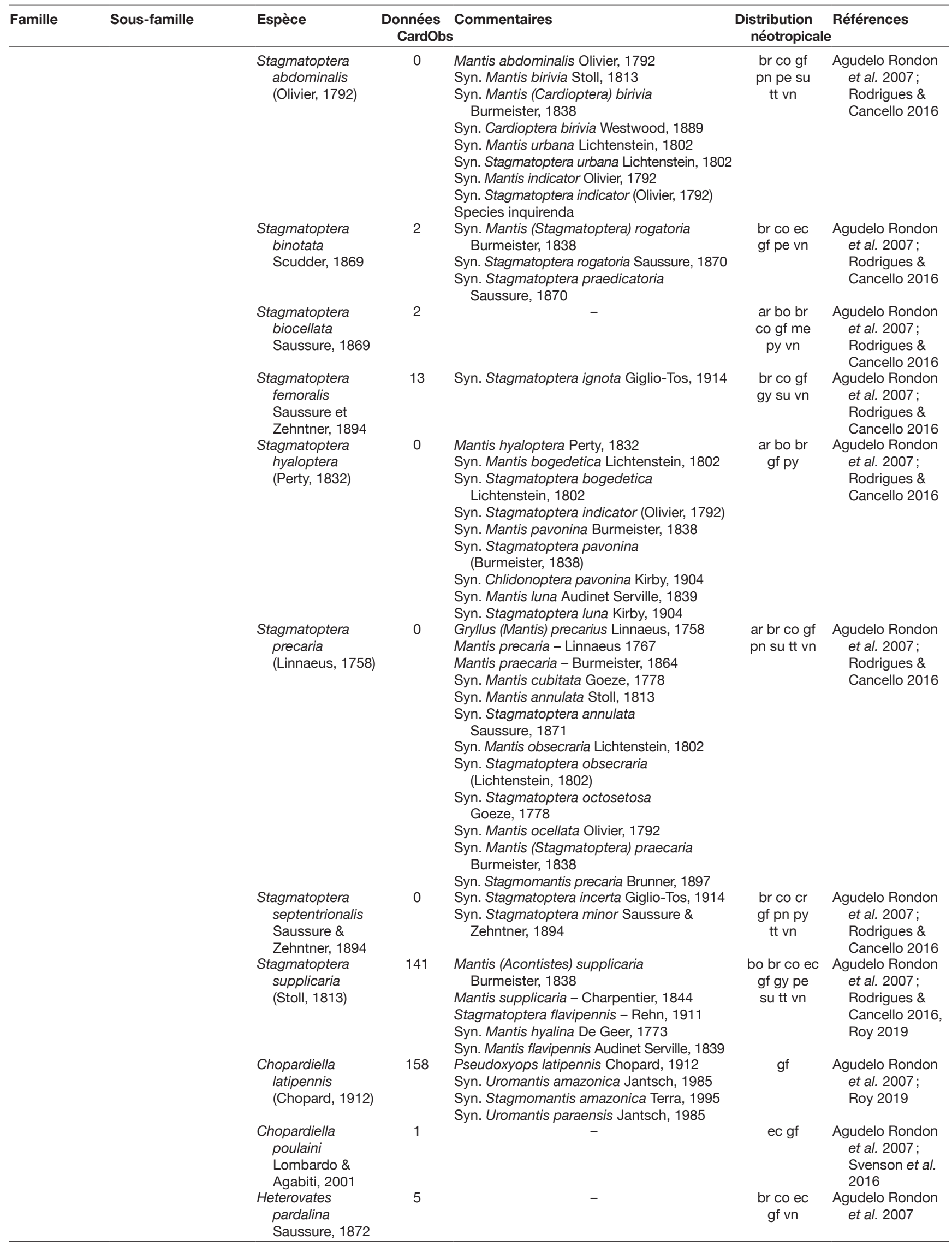


TABLEAU 2. - Suite.

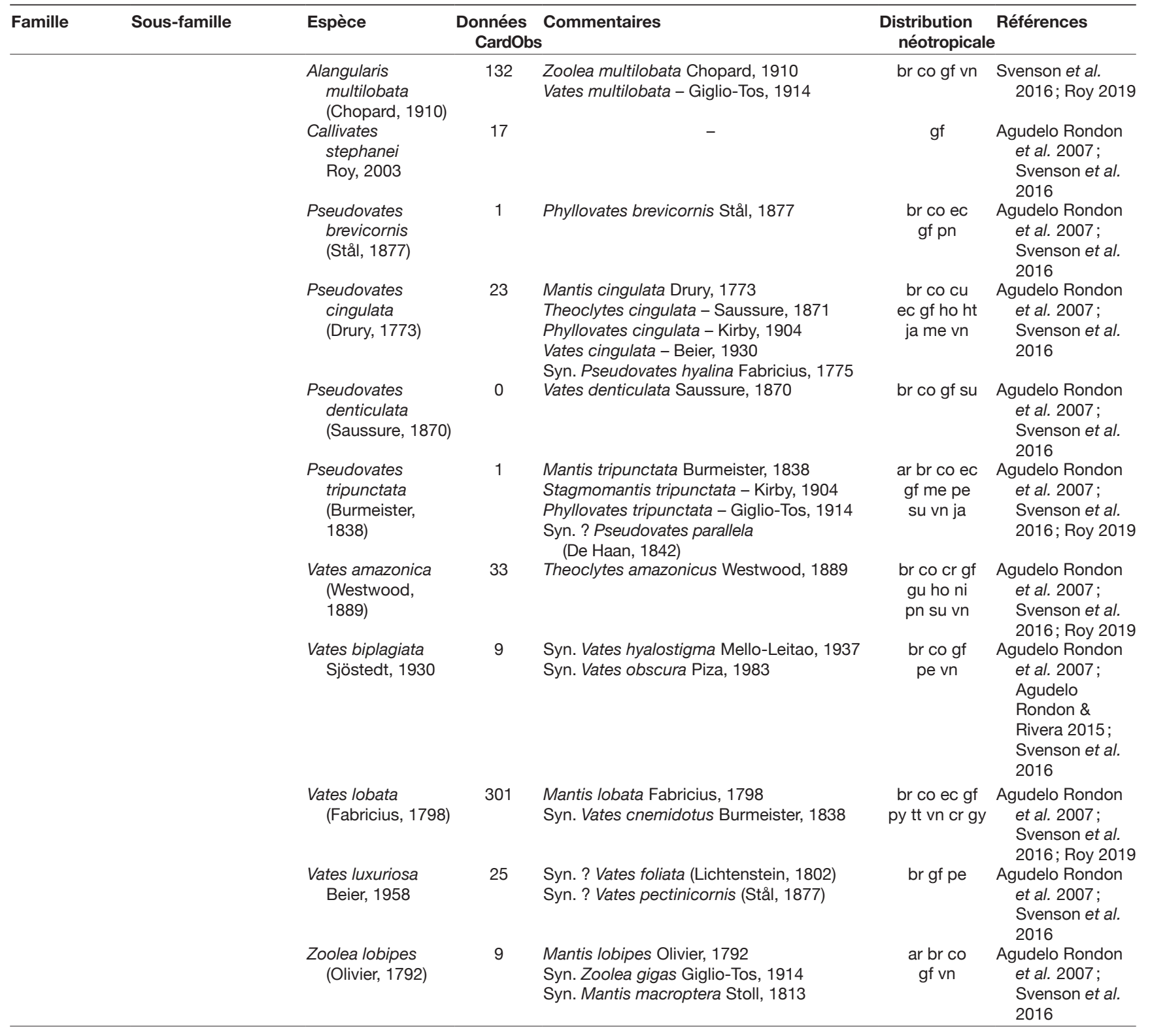

Leptomiopteryx argentina Beier, 1930 est citée par erreur de Guyane (Ehrmann 2002; Agudelo Rondon et al. 2007). Les mentions de Pseudomiopteryx spinifrons Saussure, 1870, dans Terra (1995) et dans Ehrmann (2002) sont probablement à rapporter à Pseudomiopteryx guyanensis Chopard, 1912. P. spinifrons n'est donc pas considérée comme présente en Guyane. Angela werneri (Chopard, 1914) décrite de Guyane anglaise comme Thespis, est citée de façon erronée de Guyane (Terra 1995; Ehrmann 2002; Agudelo Rondon et al. 2007).

Stagmomantis carolina (Johansson, 1763), qui a connu un nombre considérable de synonymies, est citée erronément de Guyane par Ehrmann (2002) et Agudelo Rondon et al. (2007). La citation de Parastagmatoptera confusa Giglio-Tos, 1914 en Guyane est une erreur de la part de
Agudelo Rondon et al. (2007). Cette espèce a été mise en synonymie de Parastagmatoptera pellucida Giglio-Tos, 1914 par Lombardo et al. (2015). Dans ce même article, Parastagmatoptera hoorie (Caudell, 1910), citée de Guyane par Agudelo Rondon et al. (2007), est mise en synonymie de Parastagmatoptera flavoguttata (Audinet-Serville, 1838). Ensuite, Parastagmatoptera serricornis Kirby, 1904 et Parastagmatoptera tessellata Saussure \& Zehntner, 1894 sont mises en synonymie de Parastagmatoptera unipunctata (Burmeister, 1838). Enfin, Parastagmatoptera zernyi Beier, 1930 est citée par erreur de Guyane dans Agudelo Rondon et al. (2007), elle est seulement connue de l'état Amazonas du Brésil. Stagmatoptera flavipennis (Audinet-Serville, 1838) est réinstallée en synonymie de Stagmatoptera supplicaria (Stoll, 1813) par Rodrigues \& Cancello (2016). 


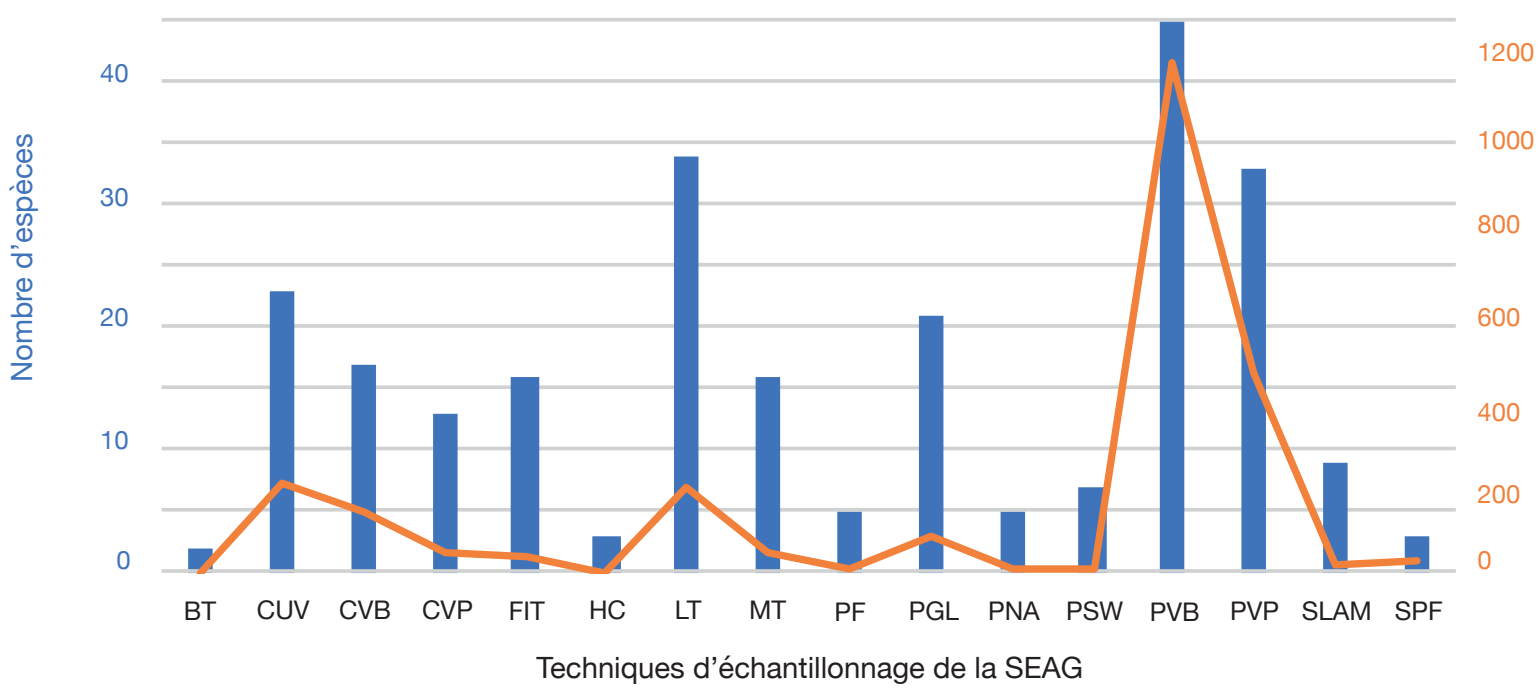

FIG. 4. - Nombre d'espèces et de spécimens collectés selon les différentes techniques d'échantillonnage de la Société Entomologique Antilles-Guyane (SEAG). Les techniques d'échantillonnage sont présentées dans le Tableau 1.

Dans Svenson et al. (2016), Phyllovates parallela (De Haan, 1842) est redéfinie comme Pseudovates parallela; et n'est plus considérée comme présente en Guyane à la différence de ce qui est noté dans Agudelo Rondon et al. (2007); de même pour Pseudovates denticulata (Saussure, 1870). Vates pectinata Saussure, 1871 et Vates pectinicornis (Stål, 1877) sont considérées comme espèces valides dans Svenson et al. (2016). Elles sont citées de Guyane dans Agudelo Rondon et al. (2007). Cependant, il apparaît que ce sont des erreurs. Elles ne sont, ici, plus considérées comme présentes dans le Département jusqu’à de prochaines collectes de spécimens. Zoolea guerinii Giglio-Tos, 1914 est considérée comme présente en Guyane par Agudelo Rondon et al. (2007). Cependant, elle a été confondue avec Zoolea orba (Burmeister, 1838). Dans Roy \& Ehrmann (2009) Zoolea guerinii n'est plus considérée comme espèce valide et est mis en synonymie de $Z$. orba. Cependant, cette espèce ne peut être considérée comme présente sur la Guyane.

Cardioptera brachyptera Burmeister, 1838 a été citée par erreur de Guyane par Agudelo Rondon et al. (2007). C'est en fin de compte une confusion avec Cardioptera squalodon Werner, 1925. C'est seulement cette dernière qu'il faut prendre en compte en Guyane. Photina vitrea (Burmeister, 1838) citée par Chopard (1912) en Guyane est une confusion avec Metriomantis pilosella (Giglio-Tos, 1915). Il ne faut donc plus la considérer comme présente dans le Département.

Les mentions en Guyane de Choeradodis rhombicollis (Latreille, 1833) et de Choeradodis stalii Wood-Mason, 1880, dans Ehrmann (2002) et Agudelo Rondon et al. (2007) sont très probablement à rapporter à Choeradodis rhomboidea (Stoll, 1813) (Roy 2004). Il ne faut donc plus les considérer comme présentes dans le Département.

Enfin, une espèce étonnante a longtemps été citée de Cayenne et du Suriname, Iris strigosa (Stoll, 1813) = Iris fasciata (Olivier, 1792). Cette erreur a été maintenue jusque dans les dernières synthèses sur les Mantes (Ehrmann 2002; Otte \& Spearman 2005). Cependant, Burmeister (1838) avait bien indiqué que les spécimens conservés au «Musée royale [sic]» provenaient d'Asie (Java, Amboina, Tranquebar). Il ne faut donc plus citer cette espèce comme présente dans le département français sudaméricain.

Alors que ces précédentes espèces ne sont plus à prendre en compte dans l'inventaire de la Faune des Mantes de Guyane, les espèces suivantes peuvent l'être, avec des réserves de confirmation de présence ou d'affirmation de synonymie pour certaines. Actuellement, Acontista cayennensis Saussure \& Zehntner, 1894 , est conservée comme espèce potentiellement présente en Guyane. Elle est citée du Brésil dans Ehrmann (2002). Cependant, aucune publication ne justifie cette répartition depuis Terra (1995), qui ne la citait que de Guyane. De plus, depuis le seul spécimen femelle originaire de Cayenne qui a servi à la description originelle, il semble qu'il n'y ait jamais eu de nouvelles captures de cette espèce. Le type, en mauvaise état, est conservé au Muséum d'Histoire naturelle de Genève. Acontista maroniensis Chopard, 1912, connue comme présent en Guyane, est très proche morphologiquement. Une comparaison des types de ces deux espèces serait nécessaire.

De même, pour Bantiella fusca Giglio-Tos, 1915, citée de Guyane par différents auteurs (Terra 1995; Ehrmann 2002; Agudelo Rondon et al. 2007) n'a, jusqu'à aujourd'hui, jamais été collectée de nouveau dans le Département. De plus, le type est originaire de Trinidad et Tobago, ce qui semble surprenant de la rencontrer en Guyane, même si les vents violents qui soufflent dans les Antilles peuvent déplacer des individus espèces d'une île à une autre; en particulier pour les espèces petites, fines et grêles comme celles appartenant aux genres Bantia Stål, 1877, Bantiella Giglio-Tos, 1915, 
Chaeteessa Burmeister, 1838, Mantoida Newman, 1838, Vespamantoida Svenson \& Rodrigues, 2019 (Wieland \& Schütte 2011). Sa présence reste à confirmer avec des spécimens en collection ou avec de nouvelles collectes.

Promiopteryx granadensis (Saussure, 1870) décrite de Colombie, mais citée de Guyane par Giglio-Tos (1927), Beier (1935), Terra (1995), Ehrmann (2002) et Agudelo Rondon et al. (2007), devrait être confirmée en Guyane. L'espèce Musonia lineata (Chopard, 1912) a été décrite comme Mionyx d'après une seule femelle provenant de Saint-Laurent du Maroni. On ne connait pas de récoltes récentes de cette espèce. Sa présence serait à confirmer. De même pour l'espèce Musonia fuscescens (Chopard, 1912) décrite par une petite série de mâles et de femelles provenant de Saint-Laurent du Maroni, La Forestière et Nouveau Chantier, n’a pas été retrouvée depuis. La présence de l'espèce en Guyane est à confirmer.

Angela quinquemaculata (Olivier, 1792), notée A. quinquimaculata dans Terra (1995), a été décrite du Suriname sur la base d'un mâle. Par la suite, Chopard (1912) cite deux mâles de Saint-Jean du Maroni. Cependant, ces deux spécimens n'ont pas été retrouvés dans les collections du MNHN. On ne connaît pas d'autres spécimens. Sa présence en Guyane est à confirmer.

Oxyopsis saussurei Giglio-Tos, 1914, décrite du Suriname d'après une femelle, est probablement synonyme avec Oxyopsis rubicunda (Stoll, 1813), les explications de Giglio-Tos n'étant pas convaincantes pour en faire la distinction.

Stagmatoptera abdominalis (Olivier, 1792) a été nommée d'après une femelle provenant du Suriname, représentée sur la figure 31 dans Stoll (1787). Cette espèce est maintenue présente en Guyane comme indiquée par Rodrigues \& Cancello (2016). Cependant, elle reste énigmatique, species inquirenda. Aucune capture récente n'est à signaler. D'après la même publication, Stagmatoptera hyaloptera (Perty, 1832) est maintenue comme présente en Guyane, mais avec un doute émis concernant un mauvais étiquetage des spécimens notés de Guyane et conservés au Muséum d'Histoire naturelle de Genève. Stagmatoptera precaria (Linnaeus, 1758), nommée Gryllus (Mantis) precarius d'après une femelle du Suriname représentée sur la planche 66 de Merian (1730), a été citée à tort par Olivier (1792) sur la représentation de la figure 62 de Stoll (1787). Chopard (1912) la cite pour la première fois du nord de la Guyane. Cependant, elle n'a pas été revue depuis.

Metriomantis ovata Saussure \& Zehntner, 1894 est considérée présente en Guyane à partir de syntypes conservés au MNHN. Cependant, une confusion existe largement dans la distinction de cette espèce avec Metriomantis pilosa (Chopard, 1912), indiquée comme espèce valide dans Roy (2006b). M. ovata est maintenue comme présente en Guyane mais des recherches supplémentaires sont à effectuer afin de les distinguer. En effet, M. pilosa, décrite comme Photina sur trois mâles de Guyane, est une espèce de grande taille $(53-55 \mathrm{~mm})$ au pronotum allongé $(16,5-17 \mathrm{~mm})$, tandis que $M$. ovata est décrite sur une femelle unique, également de Guyane, mais nettement plus petite $(39 \mathrm{~mm})$ et ave un pronotum court $(8,2 \mathrm{~mm})$ (Roy 2006b). Photina amplipennis
Stål, 1877 a été décrite sur femelle «Patria ignota». L'auteur a indiqué "Brasilia, Guyana», ce qui a été repris successivement en précisant Guyane française et en ajoutant Bolivie et Vénézuela par Agudelo Rondon et al. (2007).

Enfin, grâce au travail très complet de Lombardo et al. (2015) concernant le genre complexe des Parastagmatoptera, Parastagmatoptera immaculata Chopard, 1912 est considérée comme une espèce à part entière et non plus une forme de Parastagmatoptera flavoguttata (Audinet-Serville, 1838).

L'ensemble des données collectées et rassemblées sous CardObs permettent d'obtenir la courbe de raréfaction (Fig. 3A) qui nous indique l'efficacité (la richesse spécifique) de notre échantillonnage par rapport au nombre de spécimens collectés. La Figure 3B est une courbe de raréfaction du pourcentage d'individus présents dans le jeu de données (couverture d'échantillonnage) qui appartiennent aux espèces observées en fonction de l'intensité d'échantillonnage. Cela permet de confirmer l'efficacité de notre échantillonnage afin de mettre en évidence les espèces dominantes. Enfin, la Figure 3C nous indique le nombre d'espèces que l'on peut s'attendre à avoir en améliorant la couverture de l'échantillonnage.

\section{ANALYSES ÉCOLOGIQUES}

$55,3 \%$ de ces données (2448 spécimens) proviennent des collectes massives de la SEAG. Chacune de ces données a une technique de collecte associée et une date précise. Ces informations permettent d'obtenir les résultats suivants. Ils sont significatifs ou non selon le nombre de spécimens collectés. Les données anciennes et les observations occasionnelles ne sont pas incluses dans cette analyse. En effet, la distinction entre les différentes techniques de prospections pour l'obtention des spécimens n'est pas forcément indiquée avec les spécimens anciens. Les observations ponctuelles ne sont pas uniformes avec les données de la SEAG.

Les pièges de type PVB et PVP sont tout aussi efficaces que la chasse nocturne traditionnelle en termes de nombre de spécimens collectés. Le plus grand nombre d'espèces est collecté avec les PVB (Fig. 4).

D'après ces mêmes techniques d'échantillonnage de l'entomofaune de la SEAG, le sex-ratio des Mantes capturées est représenté ici (Fig. 5). Il est facile de remarquer que les mâles sont collectés en très grande proportion par rapport aux femelles quelle que soit la technique; sauf avec le piège barber d'interception (BT) et la chasse à vue (HC). Pour ces deux dernières techniques le nombre de spécimens collectés est faible.

La prospection à vue (de nuit comme de jour) est de loin la technique qui permet d'observer le plus de juvéniles et de femelles (Figs 6, 7, 8).

Grâce à un échantillonnage étalé sur les douze mois de l'année, les données de la SEAG permettent d'illustrer la distribution annuelle de 10 espèces communes en Guyane (Figs 9, 10). Ce sont les observations d'adultes qui sont représentées ici. Sachant que des individus juvéniles peuvent être visibles le reste de l'année selon les espèces. La durée de la phase d'incubation des œufs en oothèque est également variable selon les espèces et les conditions environnementales. 


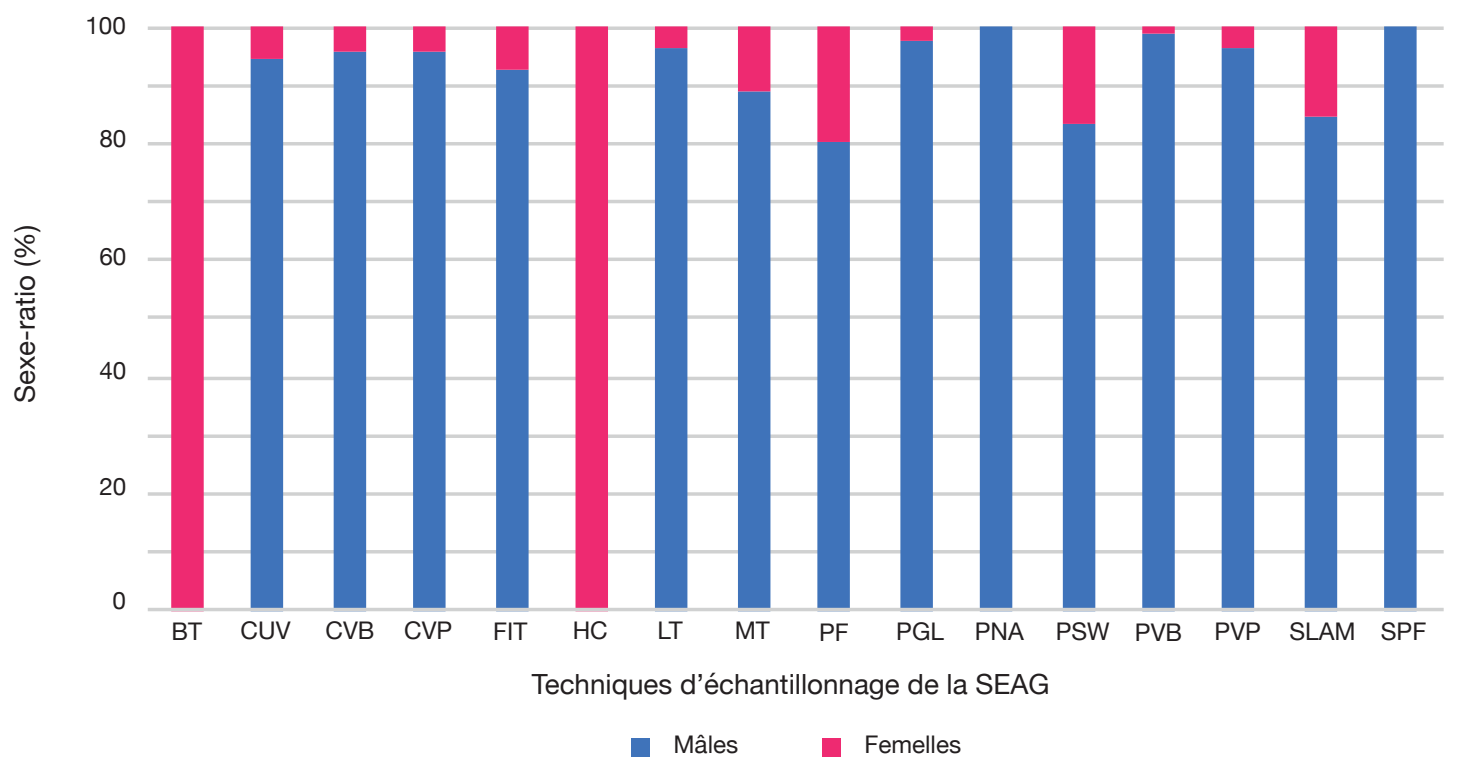

FIG. 5. - Sexe-ratio des adultes de Mantodea collectés grâce aux différentes techniques d'échantillonnage de la Société Entomologique Antilles-Guyane (SEAG). Ces dernières sont présentées dans le Tableau 1.

Lespèce la plus commune, Raptrix perspicua (Fabricius, 1787), se rencontre toute l'année avec une abondance plus marquée au début de la petite saison des pluies, fin novembre. Mantoida brunneriana (Saussure, 1871) connaît un pic d'abondance autour du mois de janvier. Le reste de l'année, elle se rencontre moins fréquemment. Parastagmatoptera flavoguttata (Audinet-Serville, 1838) se rencontre plus fréquemment durant la grande saison sèche, courant septembre. Metriomantis pilosa (Chopard, 1912) se rencontre vraisemblablement de manière très ponctuelle durant le mois de septembre. Alangularis multilobata (Chopard, 1910) doit avoir une croissance rapide car des pics d'observations d'adultes sont visibles une grande moitié de l'année, sauf durant la grande saison des pluies. De façon encore plus marquée que la précédente espèce, Chopardiella latipennis (Chopard, 1912) s'observe par pics d'abondance durant toute l'année. Metriomantis pilosella Giglio-Tos, 1915, connaît deux pics d'abondance, en septembre et en décembre. Les observations sont beaucoup moins marquées durant la grande saison des pluies. Oxyopsis rubicunda (Stoll, 1813) se rencontre préférentiellement à la fin de la grande saison des pluies. Elle semble beaucoup moins visible à l'état adulte le reste de l'année. Parastagmatoptera immaculata Chopard, 1912, suit le même schéma de répartition dans l'année que Parastagmatoptera flavoguttata, avec un pic en septembre et un autre en décembre/janvier. Angela guianensis Rehn, 1906, a été représentée car facilement reconnaissable les ailes postérieures ouvertes; même si c'est l'espèce avec le moins de spécimens collectés. Elle semble, comme l'espèce précédente, plus abondante en septembre et janvier.

\section{CODES-BARRES ADN}

Une première bibliothèque de référence de barcodes (BINs) de Mantes de Guyane a pu être mise en œuvre dans le cadre de ce projet d'amélioration des connaissances de la biodiversité française (Tableau 3).
250 séquences ont été obtenues (deux d'entre elles sont exclues des analyses du fait de leur invraisemblance) à partir de l'ADN de 299 spécimens soumis au séquençage (Fig. 11) correspondant à 82 BINs. Le pourcentage de réussite des PCR est de 83,61\%. Quatre espèces ont été soumises au séquençage sur la base de plusieurs spécimens sans résultats: Callibia diana (Stoll, 1813), Leptomiopteryx dispar Chopard, 1912, Macromusonia conspersa (Saussure, 1870), Pseudomiopteryx guyanensis.

47 BINs sont concordants avec les espèces identifiées. Enfin, $35 \mathrm{BIN}$ s sont des singletons où il faut différencier le spécimen unique séquencé et les numts.

Le problème des séquences numt est illustré à la Figure 12. Certaines espèces ont plusieurs BINs attribués. Il est nécessaire d'étudier la position des espèces dans l'arbre de rapprochement produit sur BOLD afin de confirmer les BINs d'une espèce.

\section{DISCUSSION}

Globalement, nous connaissons aujourd'hui la grande majorité des espèces de Mantes se développant en Guyane comme l'indique la courbe de raréfaction. Le plateau est atteint avec les données saisies sous CardObs. Ces données sont basées sur la taxonomie morphologique. C'est donc sans compter les espèces dont les identifications ou présences sont douteuses et les résultats du séquençage $\mathrm{ADN}$ de près de 300 spécimens. Le pourcentage de réussite des PCR est assez élevé. Cependant, il n'atteint pas $100 \%$ du fait de l'âge des spécimens en collection, des spécimens ramollis pour être montés sur épingles et des potentielles contaminations.

De plus, il est aussi important de distinguer la diversité intraspécifique de la diversité cryptique potentielle. Pour exemple, il est difficile de distinguer les numts des séquences concernant 


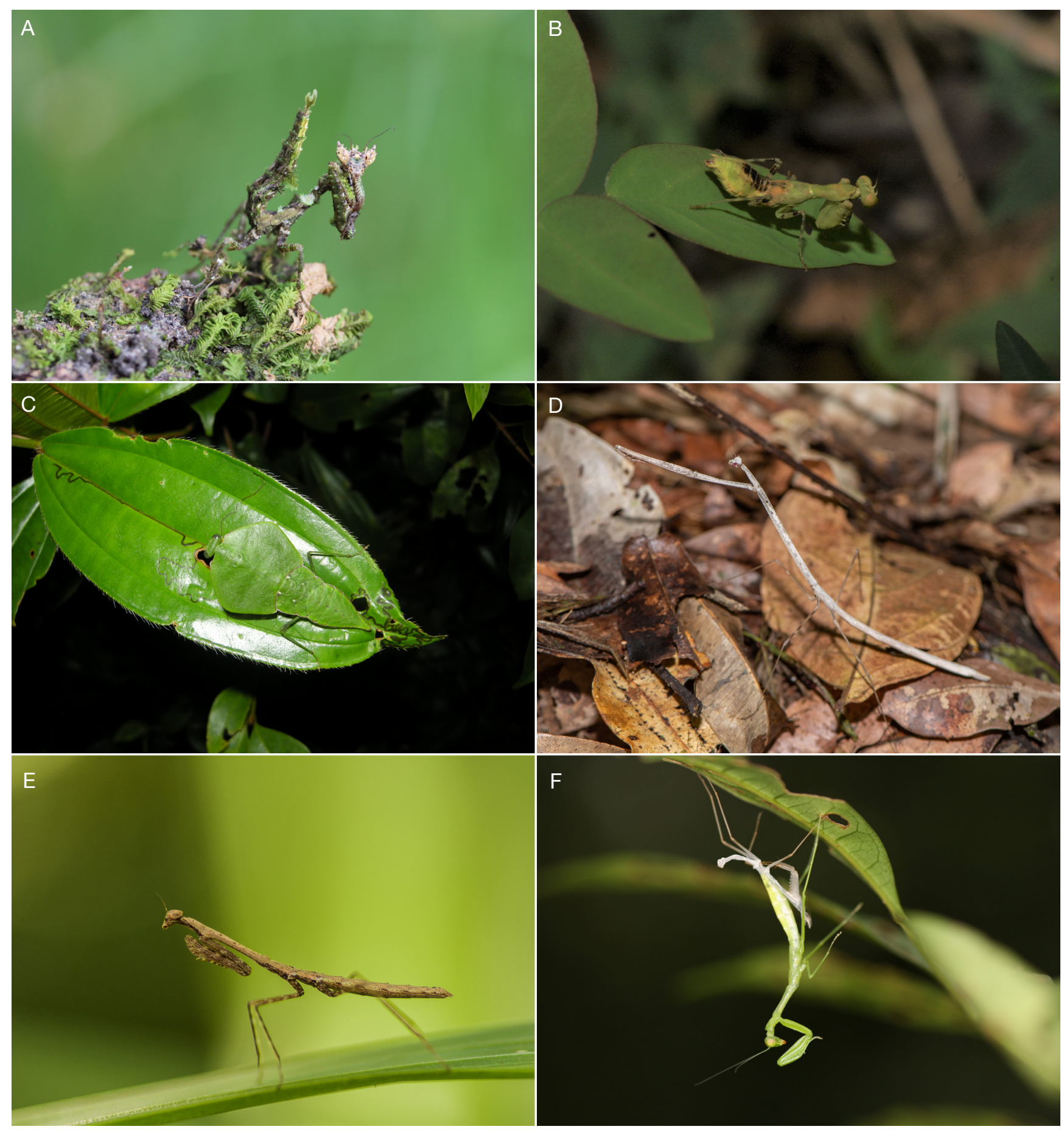

Fig. 6. - Juvéniles observés à vue: A, Pseudacanthops spinulosa (Saussure, 1870), Montagne des Chevaux, 2 mars 2019; B, Acontista maroniensis Chopard, 1912, Papaïchton, 6 septembre 2018; C, Choeradodis rhomboidea (Stoll, 1813), Saint Elie, 4 août 2015; D, Angela sp., Montagne des Singes, 16 mars 2019 ; E, Leptomiopteryx dispar Chopard, 1912, Crique Kourouaï, 30 octobre 2013; F, Microphotina sp., Montagne des Chevaux, 25 décembre 2008. Crédits photos: J. Lapèze (A), N. Moulin (B), T. Jourdan (C), V. Prémel (D), O. Bianchimani (E) \& S. Brûlé (F).

l'espèce Alangularis multilobata (Fig. 12A). Il serait intéressant de séquencer des spécimens supplémentaires afin de valider le BIN correspondant à l'espèce et de cartographier la répartition des BINs afin d'interpétrer si les différences sont associées à des distances géographiques ou à des populations différentiées. En comparaison, la diversité génétique chez Vates lobata n'entraine pas la production de BIN discordant (Fig. 12B). Enfin, le bar- coding peut à la fois confirmer des BINs pour des espèces et révéler des problématiques pour d'autres lorsque l'on étudie un genre dans son ensemble. Ici, dans le genre Microphotina (Fig. 12C), l'espèce récemment décrite du massif de Mitaraka est représentée par le BIN BOLD:ADY3505; alors que les deux autres espèces sont encore partagées entre plusieurs BINs qui représentent soit de la diversité cryptique, soit des numts. 

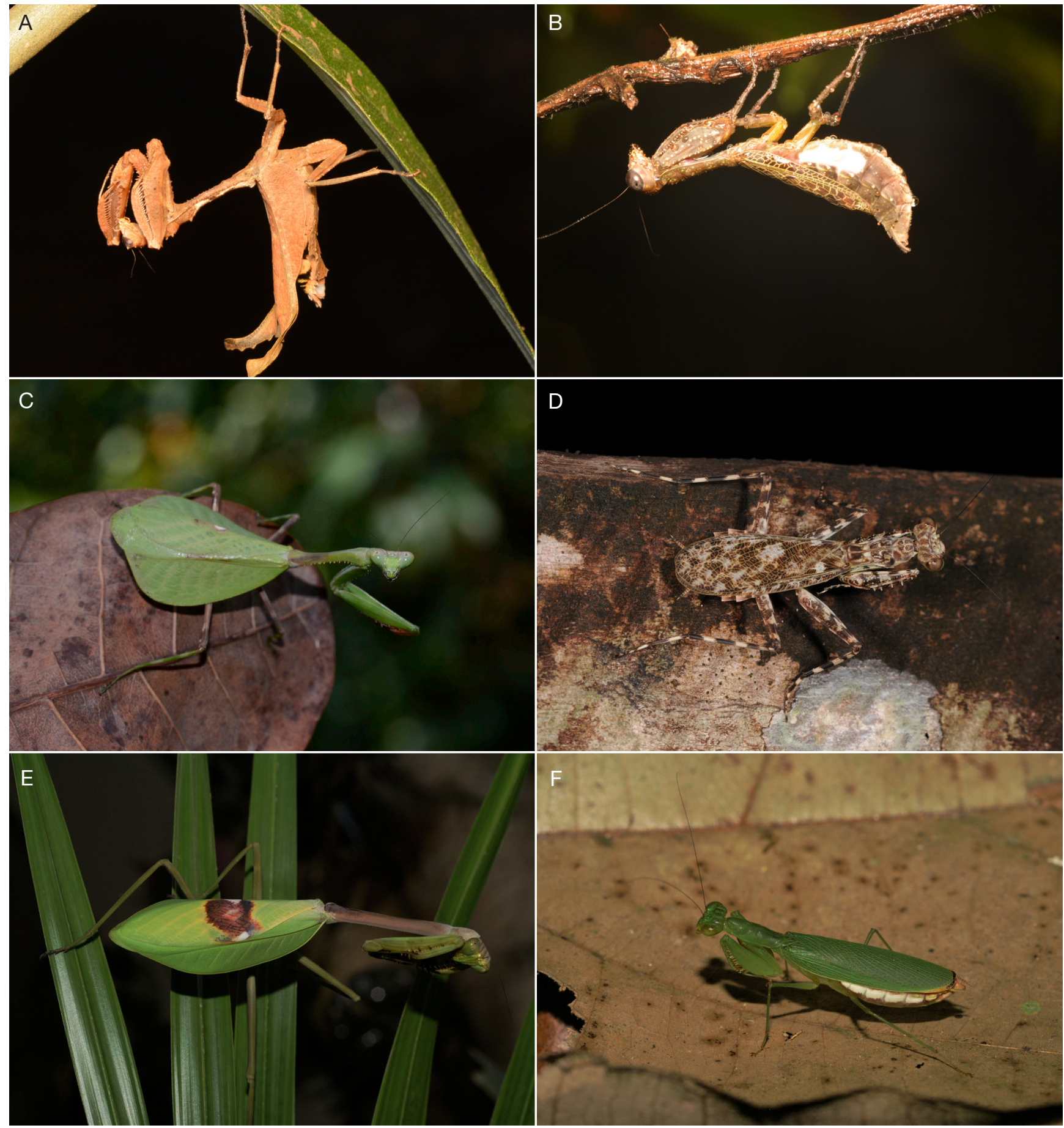

FIG. 7. - Femelles observées à vue: A, Acanthops fuscifolia (Olivier, 1792), Montagne de Kaw, 26 octobre 2014; B, Paratithrone royi Lombardo, 1996, Mitaraka, 14 mars 2015; C, Chopardiella latipennis (Chopard, 1911), Saut Mapaou, 16 août 2016; D, Liturgusa cayennensis (Saussure, 1869), 3 mars 2014; E, Stagmatoptera supplicaria (Stoll, 1813), 8 novembre 2018; F, Tithrone roseipennis (Saussure, 1870), 8 novembre 2018. Crédits photos: S. Hugel (A, B), J. Touroult (C), T. Decaëns (D) \& N. Moulin (E et F).

Ces résultats vont donc entraîner des recherches supplémentaires afin de comprendre la diversité cryptique qui existe chez certaines espèces ou confirmer une diversité génétique intraspécifique. En effet, ces dernières années une espèce nouvelle a été tout de même découverte, Microphotina viridula Roy, 2019, dans le massif du Mitaraka; et un genre nouveau, Ovalimantis, sur la Montagne des Chevaux, site largement prospecté en Guyane.
La taxonomie utilisée dans cette synthèse est celle en vigueur. Des synonymies pourraient encore être mises en place pour les espèces dont des spécimens n'ont pas encore été retrouvés depuis leur découverte.

Les différentes techniques d'échantillonnage de la SEAG permettent de caractériser les traits écologiques de nombreuses espèces car les prospections sont réparties tout au 


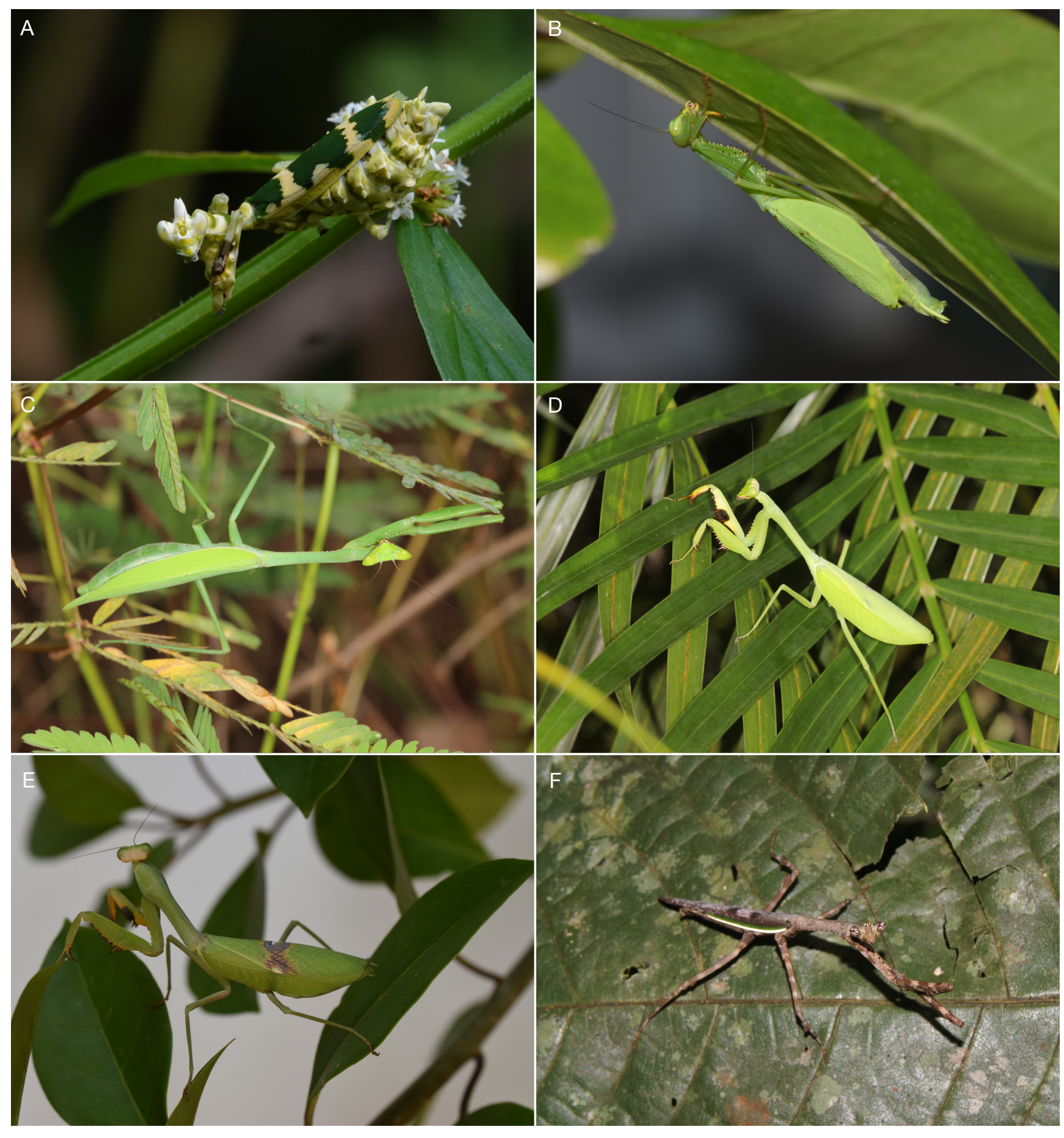

FIG. 8. - Femelles observées à vue: A, Callibia diana (Stoll, 1813), Montagne Maripa, 2 mars 2019; B, Metriomantis sp. 14 octobre 2018; C, Oxyopsis rubicunda (Stoll, 1813), Montsinéry, 29 mars 2013; D, Stagmatoptera femoralis Saussure \& Zehntner, 1894, Cayenne, 26 avril 2012; E, Stagmatoptera biocellata Saussure, 1869 , femelle adulte, Montsinéry, Guyane, 28 avril 2018; F, Vates amazonica (Westwood, 1889), Papaïchton, 6 novembre 2018. Crédits photos: N. Page (A), E. Loeb \& N. Haussher (B, E), S. Brûlé (C, D) \& N. Moulin (F).

long de l'année. Les pièges aériens d'interception (attractifs ou non) tels que les PVB sont très efficaces. Cependant, cela nécessite la collecte d'un très grand nombre de spécimens, souvent communs, à la différence des autres techniques où le nombre de spécimens collectés reste plus faible par rapport au nombre d'espèces représentées. En particulier pour la chasse nocturne traditionnelle où plusieurs hypothèses peuvent être envisagées: soit les entomologistes présents choisissent le nombre de spécimens à collecter selon les espèces présentes, soit les spécimens qui arrivent au drap sont tous collectés alors que certains spécimens peuvent potentiellement s'échapper des divers pièges automatiques. Les pièges CUV, CVB et CVP devraient tendre vers les mêmes efficacités. Ils n'ont été mis en route, principalement 

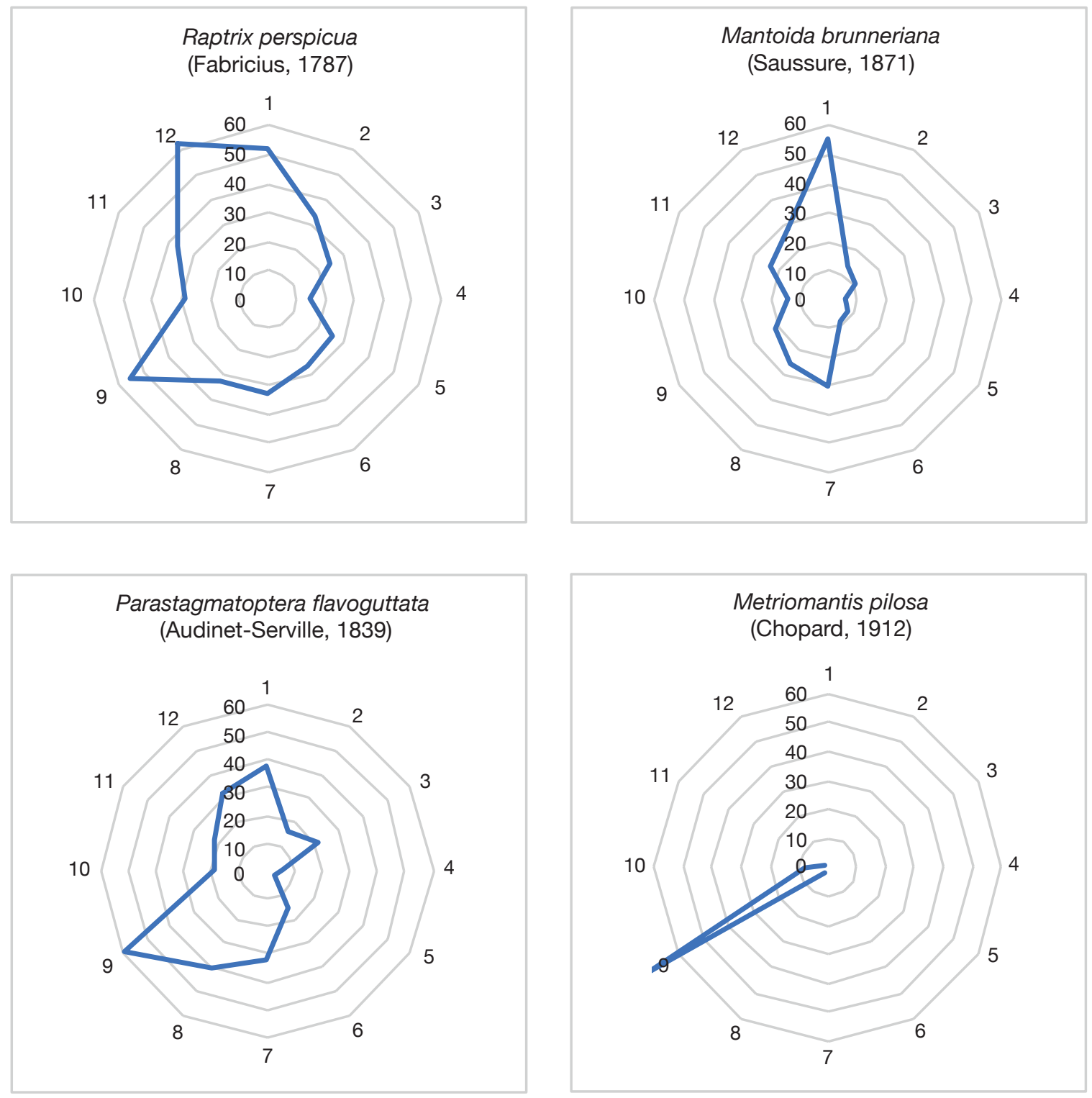

FIG. 9. - Répartition annuelle de quatre espèces communes de Mantes en Guyane. Les nombres extérieurs représentent les douze mois de l'année, les cercles les abondances et le trait bleu la répartition annuelle.

à la Montagne des Chevaux, que depuis le mois d'avril 2018 dans le cadre d'un projet d'étude de la Canopée gérée par la SEAG sur une durée d'un an. Les courbes de raréfaction montrent également que les techniques d'échantillonnage utilisées jusqu'à aujourd'hui ont atteint leurs limites. Les espèces dominantes sont largement représentées. La détection de nouvelles espèces pour la Science semble s'amoindrir. Des techniques comme la prospection à vue de nuit, fastidieuse mais importante, sont nécessaires si nous souhaitons découvrir de nouvelles espèces, ou plus simplement observer les femelles de nombreuses espèces connues uniquement par les mâles.

Ces résultats confirment encore une fois que les mâles de Mantes sont attirés efficacement par différentes sources de lumière. De plus, ils ont une capacité de voler que les femelles n'ont généralement pas comme chez les Thespidae où les femelles sont aptères. Cependant, chez une minorité d'espèces les femelles sont également capturées par des pièges lumineux automatiques comme certains Vatinae, en particulier dans le genre Parastagmatptera.

Les Mantes sont visibles, finalement, quasiment toute l'année si l'on étudie autant les jeunes que les adultes. Cependant, des pics d'abondance sont visibles chez les espèces les plus communes, selon les saisons.

\section{CONCLUSION}

Cette synthèse permet de poser de bonnes bases de connaissance concernant les Mantes de Guyane; cependant l'inventaire entomologique dans ce département est loin d'être terminé (Brûlé \& Touroult 2014). Des recherches à vue 

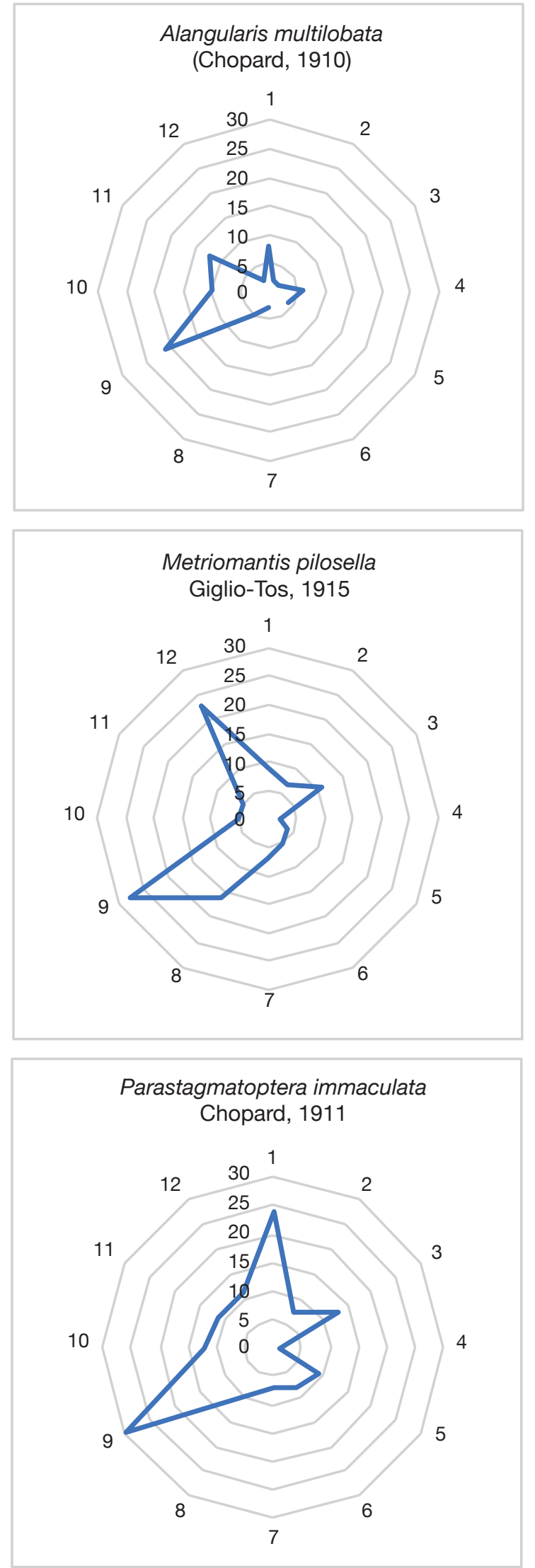
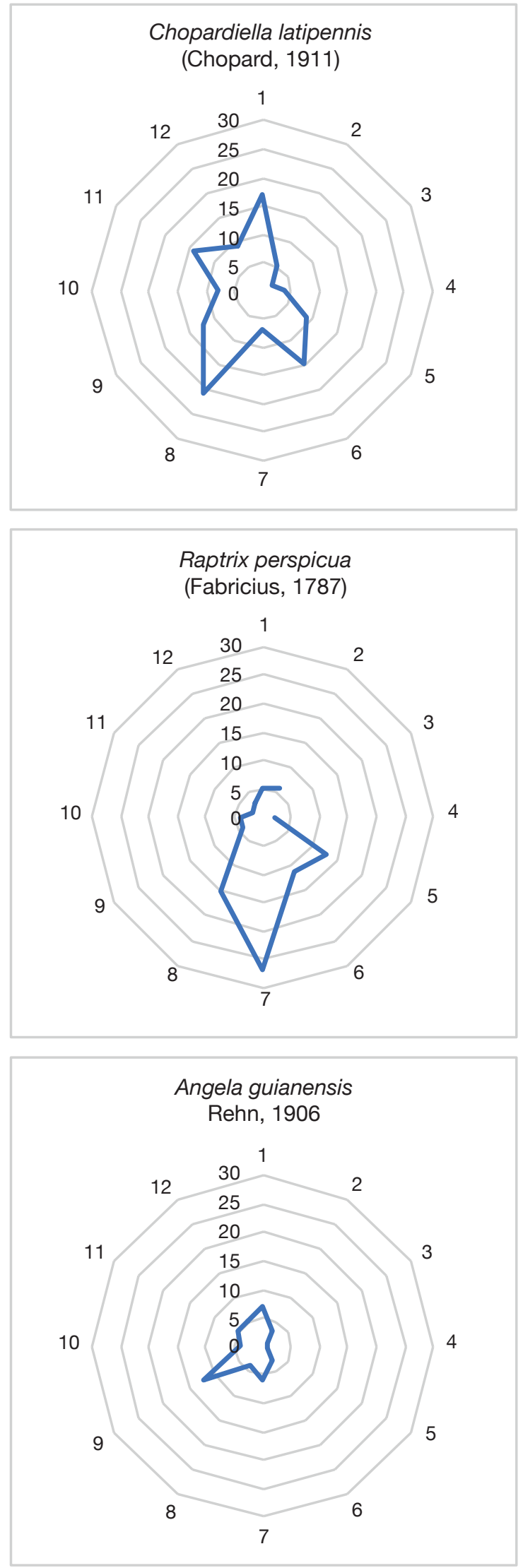

FIG. 10. - Répartition annuelle de six espèces communes de Mantes en Guyane. Les nombres extérieurs représentent les douze mois de l'année, les cercles les abondances et le trait bleu la répartition annuelle. 
TABlEAu 3. - «Barcode Index Numbers» des Mantes de Guyane. Abréviations: BIN, Barcode Index Number; DNN, distance avec l'espèce la plus proche; Imax, distance maximale; $\mathbf{N}$, nombre de séquences.

\begin{tabular}{|c|c|c|c|c|c|c|}
\hline Familles & Espèce & BIN & $\mathbf{N}$ & Imax & Espèce la plus proche & DNN \\
\hline Chaeteessidae & Chaeteessa valida (Perty, 1833) & $\begin{array}{l}\text { BOLD:ADW7620 } \\
\text { BOLD:ADW7619 } \\
\text { BOLD:ADW7618 }\end{array}$ & $\begin{array}{l}1 \\
1 \\
3\end{array}$ & $14,74 \%$ & Liturgusa cayennensis & $18,63 \%$ \\
\hline \multirow[t]{2}{*}{ Mantoididae } & Mantoida brunneriana (Saussure, 1871) & $\begin{array}{l}\text { BOLD:AAX3593 } \\
\text { BOLD:ADU1794 } \\
\text { BOLD:ADX8271 }\end{array}$ & $\begin{array}{l}8 \\
3 \\
1\end{array}$ & $8,83 \%$ & Macromantis ovalifolia & $16,15 \%$ \\
\hline & Vespamantoida toulgoeti (Roy, 2010) & $\begin{array}{l}\text { BOLD:ADT3970 } \\
\text { BOLD:ADX2817 }\end{array}$ & $\begin{array}{l}3 \\
1\end{array}$ & $3,31 \%$ & Callivates stephanei & $16,94 \%$ \\
\hline $\begin{array}{l}\text { Thespidae- } \\
\text { Bantiinae }\end{array}$ & Bantia fusca Chopard, 1911 & $\begin{array}{l}\text { BOLD:ABX4571 } \\
\text { BOLD:ADY7141 }\end{array}$ & $\begin{array}{l}1 \\
1\end{array}$ & $3,79 \%$ & Macromantis saussurei & $16,93 \%$ \\
\hline \multirow[t]{2}{*}{$\begin{array}{l}\text { Thespidae- } \\
\text { Thespinae }\end{array}$} & $\begin{array}{l}\text { Pseudomusonia maculosa } \\
\quad \text { (Chopard, 1911) }\end{array}$ & $\begin{array}{l}\text { BOLD:ADS5061 } \\
\text { BOLD:ADW3964 }\end{array}$ & $\begin{array}{l}1 \\
1\end{array}$ & $4,96 \%$ & Zoolea lobipes & $20,64 \%$ \\
\hline & $\begin{array}{l}\text { Musonia surinama (Saussure, 1869) } \\
\text { Macromusonia major (Saussure \& } \\
\text { Zehntner, 1894) }\end{array}$ & $\begin{array}{l}\text { BOLD:ADX9553 } \\
\text { BOLD:ADW9696 } \\
\text { BOLD:ACX1951 }\end{array}$ & $\begin{array}{l}1 \\
2 \\
2\end{array}$ & $\begin{array}{l}0,00 \% \\
5,35 \%\end{array}$ & $\begin{array}{l}\text { Tithrone roseipennis } \\
\text { Liturgusa milleri }\end{array}$ & $\begin{array}{l}18,02 \% \\
17,56 \%\end{array}$ \\
\hline Angelidae & $\begin{array}{l}\text { Angela armata (Haan, 1842) } \\
\text { Angela guianensis Rehn, 1906 } \\
\text { Angela lemoulti (Chopard, 1910) } \\
\text { Angela maxima (Chopard, 1910) } \\
\text { Angela purpurascens (Olivier, 1792) } \\
\text { Angela saussurii Giglio-Tos, 1927 }\end{array}$ & $\begin{array}{l}\text { BOLD:ADV0305 } \\
\text { BOLD:ACR2496 } \\
\text { BOLD:ADW3180 } \\
\text { BOLD:ACR2497 } \\
\text { BOLD:ADW1138 } \\
\text { BOLD:ADV0304 } \\
\text { BOLD:ADX8530 }\end{array}$ & $\begin{array}{l}2 \\
7 \\
2 \\
1 \\
1 \\
1 \\
6\end{array}$ & $\begin{array}{c}0,48 \% \\
1,24 \% \\
2,02 \% \\
0,00 \% \\
0,00 \% \\
13,65 \%\end{array}$ & $\begin{array}{l}\text { Angela guianensis } \\
\text { Angela armata } \\
\text { Angela purpurascens } \\
\text { Angela saussurii } \\
\text { Angela maxima } \\
\text { Angela maxima }\end{array}$ & $\begin{array}{l}16,90 \% \\
16,90 \% \\
16,90 \% \\
15,66 \% \\
15,73 \% \\
15,66 \%\end{array}$ \\
\hline \multirow[t]{3}{*}{ Liturgusidae } & $\begin{array}{l}\text { Liturgusa cayennensis (Saussure, 1869) } \\
\text { Liturgusa maroni Svenson, } 2014\end{array}$ & $\begin{array}{l}\text { BOLD:ACX2887 } \\
\text { BOLD:ADV8798 } \\
\text { BOLD:ACX2886 } \\
\text { BOLD:ADZ0563 }\end{array}$ & $\begin{array}{l}3 \\
1 \\
1 \\
1\end{array}$ & $\begin{array}{c}1,39 \% \\
11,97 \%\end{array}$ & $\begin{array}{l}\text { Liturgusa maroni } \\
\text { Liturgusa milleri }\end{array}$ & $\begin{array}{l}11,78 \% \\
2,90 \%\end{array}$ \\
\hline & Liturgusa milleri Svenson, 2014 & $\begin{array}{l}\text { BOLD:ADY4514 } \\
\text { BOLD:ADX7261 }\end{array}$ & $\begin{array}{l}2 \\
2\end{array}$ & $12,43 \%$ & Liturgusa maroni & $2,90 \%$ \\
\hline & Hagiomantis mesopoda Westwood, 1889 & BOLD:ADW3527 & 1 & $0,00 \%$ & Oxyopsis saussurei & $14,57 \%$ \\
\hline \multirow{2}{*}{$\begin{array}{l}\text { Photinaidae- } \\
\text { Macromantinae }\end{array}$} & Macromantis hyalina (De Geer, 1773) & BOLD:ADT6257 & 1 & $0,00 \%$ & Macromantis saussurei & $7,79 \%$ \\
\hline & $\begin{array}{l}\text { Macromantis ovalifolia (Stoll, 1813) } \\
\text { Macromantis saussurei Roy, } 2002\end{array}$ & $\begin{array}{l}\text { BOLD:ACR2897 } \\
\text { BOLD:ADY5988 }\end{array}$ & $\begin{array}{l}5 \\
1\end{array}$ & $\begin{array}{l}0,77 \% \\
0,00 \%\end{array}$ & $\begin{array}{l}\text { Macromantis hyalina } \\
\text { Macromantis hyalina }\end{array}$ & $\begin{array}{c}10,88 \% \\
7,79 \%\end{array}$ \\
\hline $\begin{array}{l}\text { Photinaidae- } \\
\text { Cardiopterinae }\end{array}$ & Cardioptera squalodon Werner, 1932 & BOLD:ADT3381 & 4 & $0,31 \%$ & Metriomantis pilosa & $18,05 \%$ \\
\hline \multirow[t]{5}{*}{$\begin{array}{l}\text { Photinaidae- } \\
\text { Photinainae }\end{array}$} & Microphotina viridescens (Chopard, 1912) & $\begin{array}{l}\text { BOLD:ACR2312 } \\
\text { BOLD:ADU2692 } \\
\text { BOLD:ADS8321 }\end{array}$ & $\begin{array}{l}7 \\
1 \\
3\end{array}$ & $14,13 \%$ & Microphotina viridula & $10,08 \%$ \\
\hline & Microphotina viridula Roy, 2019 & BOLD:ADY3505 & 4 & $0,18 \%$ & Microphotina viridescens & $10,08 \%$ \\
\hline & Microphotina vitripennis (Saussure, 1872) & BOLD:ADY4851 & 2 & $0,00 \%$ & Microphotina viridescens & $14,48 \%$ \\
\hline & Metriomantis pilosa (Chopard, 1912) & $\begin{array}{l}\text { BOLD:ADZ7611 } \\
\text { BOLD:ADT9180 }\end{array}$ & $\begin{array}{l}3 \\
1\end{array}$ & $9,02 \%$ & Metriomantis pilosella & $11,06 \%$ \\
\hline & Metriomantis pilosella Giglio-Tos, 1915 & BOLD:ACR3433 & 5 & $1,87 \%$ & Metriomantis pilosa & $11,06 \%$ \\
\hline \multirow{7}{*}{$\begin{array}{l}\text { Acanthopidae- } \\
\text { Acanthopinae }\end{array}$} & Acanthops fuscifolia (Olivier, 1792) & BOLD:ACP7911 & 4 & $2,36 \%$ & Plesiacanthops tuberculata & $10,85 \%$ \\
\hline & Acanthops soukana Roy, 2002 & BOLD:ADX5007 & 1 & $0,00 \%$ & Acanthops fuscifolia & $12,68 \%$ \\
\hline & Metacanthops amazonica (Beier, 1930) & BOLD:ADY0336 & 7 & $1,87 \%$ & Metilia integra & $13,76 \%$ \\
\hline & Metilia brunnerii (Saussure, 1871) & $\begin{array}{l}\text { BOLD:ACP8801 } \\
\text { BOLD:ADY2961 } \\
\text { BOLD:ADV2496 }\end{array}$ & $\begin{array}{l}1 \\
1 \\
2\end{array}$ & $6,29 \%$ & Metilia integra & $13,48 \%$ \\
\hline & Metilia integra (Stal, 1870) & BOLD:ADT1180 & 1 & $0,00 \%$ & Metilia brunnerii & $13,48 \%$ \\
\hline & $\begin{array}{l}\text { Plesiacanthops tuberculata (Saussure, } \\
\text { 1870) }\end{array}$ & BOLD:AAX4345 & 2 & $1,08 \%$ & Acanthops fuscifolia & $10,85 \%$ \\
\hline & $\begin{array}{l}\text { Pseudacanthops spinulosa (Saussure, } \\
\text { 1870) }\end{array}$ & BOLD:ACP8855 & 7 & $2,50 \%$ & Acanthops fuscifolia & $11,59 \%$ \\
\hline \multirow{4}{*}{$\begin{array}{l}\text { Acanthopidae- } \\
\text { Stenophyllinae }\end{array}$} & Acontista gracilis Chopard, 1911 & BOLD:ACR2242 & 6 & $1,08 \%$ & Tithrone roseipennis & $14,53 \%$ \\
\hline & Acontista maroniensis Chopard, 1912 & $\begin{array}{l}\text { BOLD:ADS6964 } \\
\text { BOLD:ADS3119 }\end{array}$ & $\begin{array}{l}1 \\
2\end{array}$ & $3,46 \%$ & Raptrix perspicua & $12,84 \%$ \\
\hline & Raptrix perspicua (Fabricius, 1787) & $\begin{array}{l}\text { BOLD:ACP9602 } \\
\text { BOLD:ADX8220 }\end{array}$ & $\begin{array}{l}11 \\
3\end{array}$ & $2,66 \%$ & Acontista maroniensis & $12,84 \%$ \\
\hline & Tithrone roseipennis (Saussure, 1870) & $\begin{array}{l}\text { BOLD:ADY0044 } \\
\text { BOLD:ADY0045 } \\
\text { BOLD:ADT8150 } \\
\text { BOLD:ADX4172 }\end{array}$ & $\begin{array}{l}2 \\
1 \\
1 \\
2\end{array}$ & $3,30 \%$ & Acontista maroniensis & $13,02 \%$ \\
\hline \multirow{2}{*}{$\begin{array}{l}\text { Mantidae- } \\
\text { Choeradodinae }\end{array}$} & Choeradodis rhomboidea (Stoll, 1813) & - & 1 & $0,00 \%$ & Choeradodis strumaria & $15,90 \%$ \\
\hline & Choeradodis strumaria (Linnaeus, 1758) & $\begin{array}{l}\text { BOLD:ADS3890 } \\
\text { BOLD:ADZ0458 }\end{array}$ & $\begin{array}{l}3 \\
1\end{array}$ & $4,34 \%$ & Vates lobata & $13,72 \%$ \\
\hline Mantidae-Vatinae & $\begin{array}{l}\text { Stagmatoptera biocellata Saussure, } 1869 \\
\text { Stagmatoptera supplicaria (Stoll, 1813) }\end{array}$ & $\begin{array}{l}\text { BOLD:ADX0181 } \\
\text { BOLD:ACR2427 } \\
\text { BOLD:ACR3432 } \\
\text { BOLD:ACP9203 }\end{array}$ & $\begin{array}{l}1 \\
6 \\
1 \\
1\end{array}$ & $\begin{array}{l}0,00 \% \\
8,53 \%\end{array}$ & $\begin{array}{l}\text { Stagmatoptera supplicaria } \\
\text { Stagmatoptera biocellata }\end{array}$ & $\begin{array}{l}8,17 \% \\
8,17 \%\end{array}$ \\
\hline
\end{tabular}




\begin{tabular}{|c|c|c|c|c|c|c|}
\hline Familles & Espèce & BIN & $\mathbf{N}$ & Imax & Espèce la plus proche & DNN \\
\hline & $\begin{array}{l}\text { Parastagmatoptera flavoguttata } \\
\text { (Audinet-Serville, 1839) }\end{array}$ & BOLD:ACP8537 & 13 & $1,39 \%$ & Parastagmatoptera immaculata & $5,91 \%$ \\
\hline & $\begin{array}{l}\text { Parastagmatoptera immaculata } \\
\text { Chopard, } 1911\end{array}$ & BOLD:ACR2557 & 8 & $1,08 \%$ & Parastagmatoptera flavoguttata & $5,91 \%$ \\
\hline & $\begin{array}{l}\text { Parastagmatoptera unipunctata } \\
\text { Burmeister, } 1838\end{array}$ & BOLD:ADY0831 & 3 & $2,34 \%$ & Parastagmatoptera flavoguttata & $6,23 \%$ \\
\hline & Oxyopsis rubicunda (Stoll, 1813) & BOLD:ADU8626 & 3 & $2,99 \%$ & Oxyopsis saussurei & $7,73 \%$ \\
\hline & & BOLD:ADX7118 & 1 & & & \\
\hline & Oxyopsis saussurei Giglio-Tos, 1914 & BOLD:ADU8622 & 4 & $0,46 \%$ & Oxyopsis rubicunda & $7,73 \%$ \\
\hline & Chopardiella latipennis (Chopard, 1911) & BOLD:ACP9524 & 7 & $1,71 \%$ & Parastagmatoptera unipunctata & $9,58 \%$ \\
\hline & Heterovates pardalina Saussure, 1871 & BOLD:ADX1263 & 1 & $0,00 \%$ & Alangularis multilobata & $7,90 \%$ \\
\hline & Pseudovates cingulata Drury, 1773 & BOLD:ADV1960 & 4 & $0,34 \%$ & Alangularis multilobata & $6,05 \%$ \\
\hline & Callivates stephanei Roy, 2003 & BOLD:ADY2550 & 2 & $0,31 \%$ & Vates lobata & $8,12 \%$ \\
\hline & Alangularis multilobata (Chopard, 1910) & BOLD:ADT3708 & 3 & $5,74 \%$ & Pseudovates cingulata & $6,05 \%$ \\
\hline & & BOLD:ADW8825 & 1 & & & \\
\hline & & BOLD:ADZ6024 & 4 & & & \\
\hline & Vates amazonica (Westwood, 1889) & BOLD:ADV7963 & 4 & $0,00 \%$ & Vates luxuriosa & $5,14 \%$ \\
\hline & Vates lobata (Fabricius, 1798) & BOLD:ACP9060 & 10 & $1,24 \%$ & Vates luxuriosa & $4,92 \%$ \\
\hline & Vates luxuriosa Beier, 1958 & BOLD:ACR2406 & 11 & $0,48 \%$ & Vates lobata & $4,92 \%$ \\
\hline & Zoolea lobipes (Olivier, 1792) & BOLD:ADW5526 & 1 & $0,00 \%$ & Vates lobata & $5,94 \%$ \\
\hline
\end{tabular}

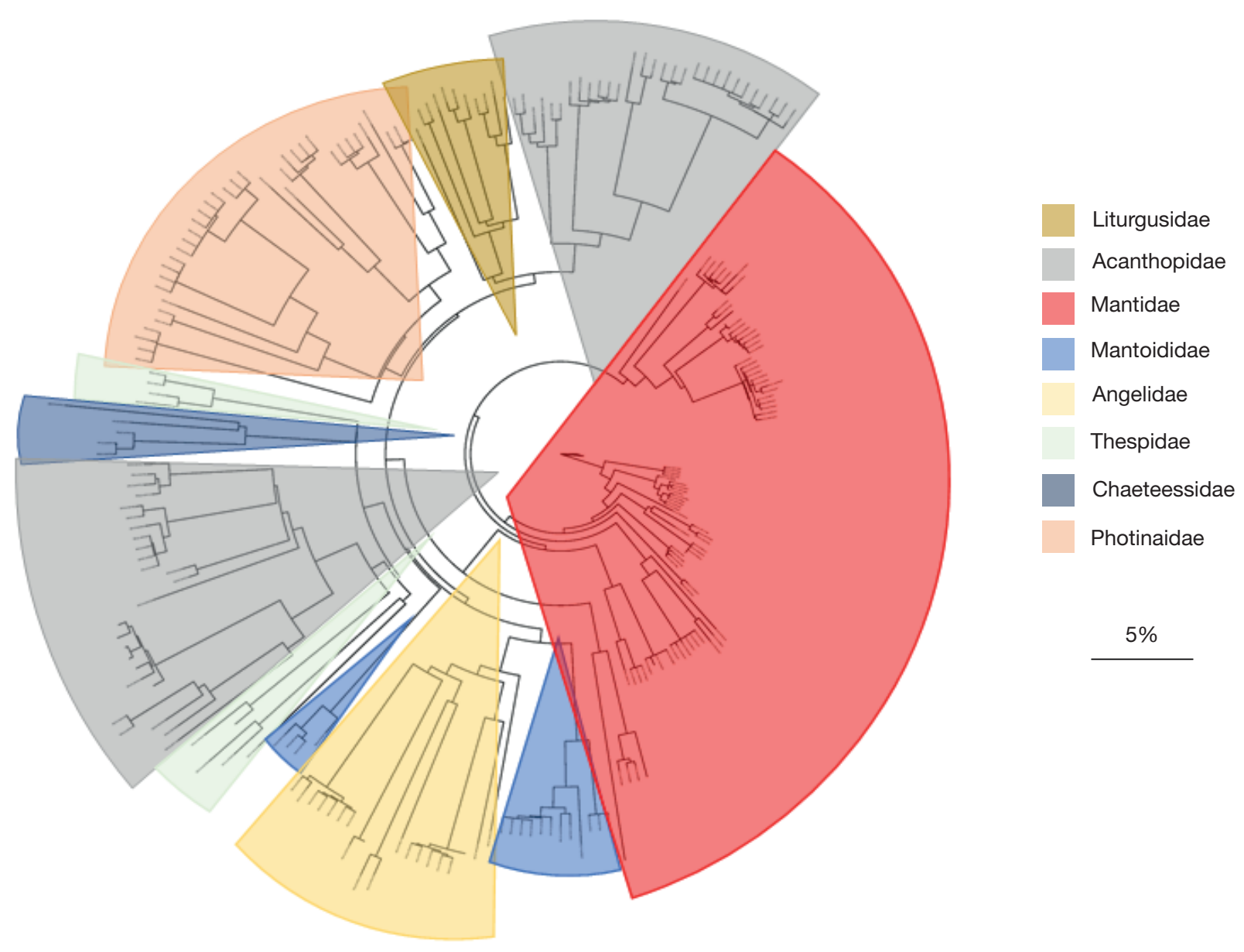

FIG. 11. - Arbre de rapprochement des 248 spécimens ayant un Barcode Index Number (BIN), obtenu sur Barcode of Life Data Systems (BOLD), organisé en phylogramme, selon les familles de Mantes représentées. 
A

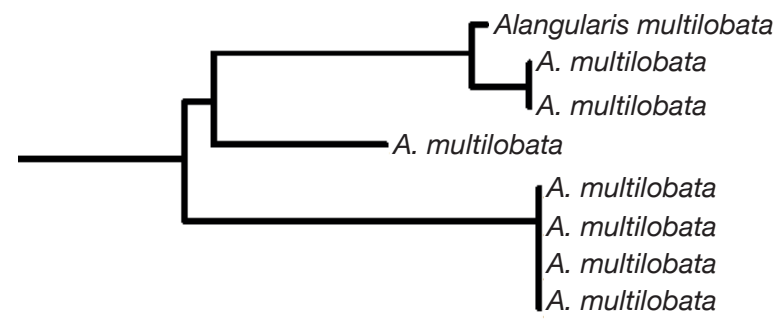

B

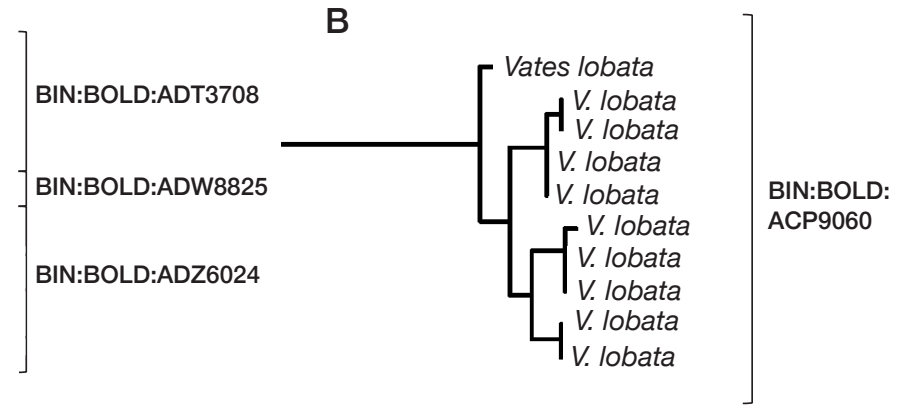

C

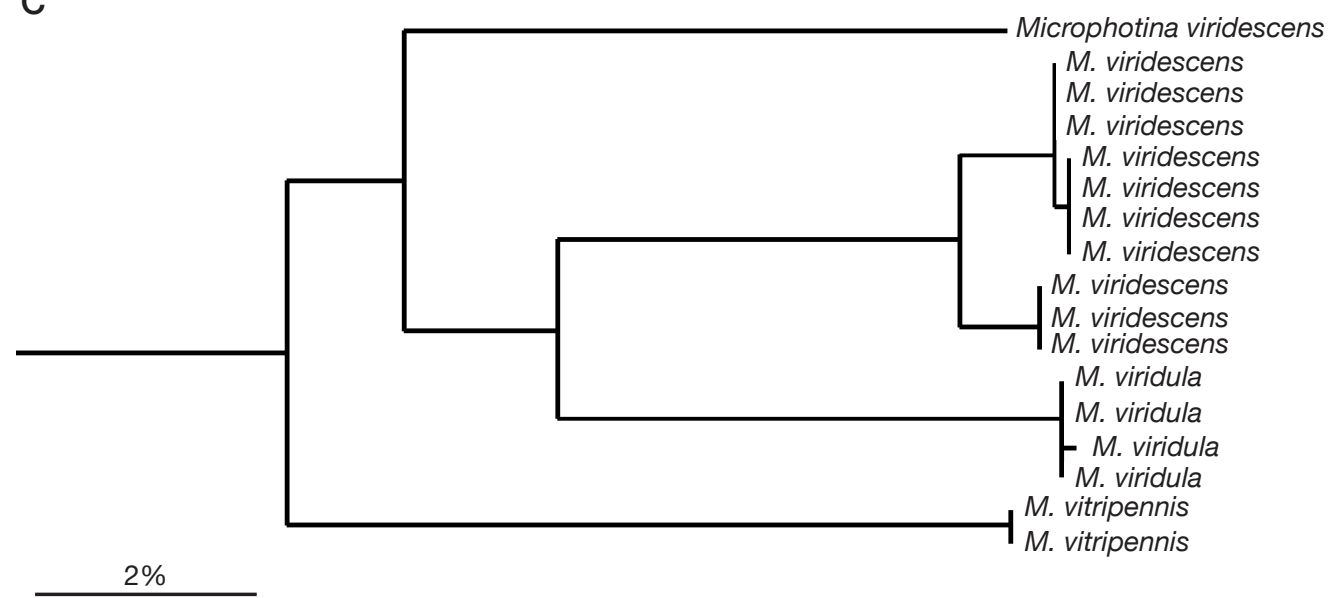

BIN:BOLD:ADU2692

BIN:BOLD:ACR2312

BIN:BOLD:ADS8321

BIN:BOLD:ADY3505

BIN:BOLD:ADY4851

FIG. 12. - Exemple de BIN discordants et des problèmes d'interprétation des potentielles séquences numt (Pseudogènes nucléaires mitochondriaux) : A, Alangularis multilobata (Chopard, 1910) comprend quatre BINs (Barcode Index Number) du fait de la forte divergence génétique entre les séquences, certains peuvent être interprétés comme des numts; B, Vates lobata (Fabricius, 1798) connaît de la diversité génétique sans que cela n'entraine la création de BIN multiple; C, le genre Microphotina, dont la distinction morphologique largement basée sur la conformation des genitalia, reste difficile à appréhender.

et/ou en canopée devraient permettre de mettre en évidence de nouvelles espèces pour la Science.

La bibliothèque de référence de séquences $\mathrm{ADN}$ permettra d'aider à la distinction entre des espèces cryptiques, à l'étude de spécimens juvéniles ou d'appariement de deux sexes d'une même espèce.

La synthèse des connaissances sur les Mantes de Guyane produite ici permettra de faciliter l'acquisition de données de terrain lors d'inventaires naturalistes. En effet, il est reconnu que la biodiversité décline localement à un rythme trop rapide. Ce déclin surpasse actuellement notre capacité à acquérir des connaissances, à exploiter ces connaissances et à proposer des solutions pour concilier développement et conservation de la biodiversité (Dewynter comm. pers.).

À l'issue de cette synthèse et de ses implications, l'objectif suivant est de produire une faune pour le Département avec des clés de déterminations (au niveau du genre et de l'espèce).

\section{Remerciements}

Ces travaux scientifiques s'inscrivent dans le cadre de l'inventaire du patrimoine naturel. Ils ont bénéficié en 2018 d'un soutien de l'UMS PatriNat (AFB, CNRS, MNHN). Nous tenons à remercier les responsables des collections Mantodea du MNHN, Philippe Grandcolas et Frédéric
Legendre; ainsi que les collègues de la SEAG qui nous ont confié un très grand nombre d'échantillons. Nous tenons à remercier tous ceux qui ont contribué de près ou de loin, en particulier, avec l'apport de photos de spécimens in natura afin d'enrichir les fiches espèces de l'INPN. Nous tenons à remercier également Quentin Rome qui a veillé au grain jusqu'à l'aboutissement de ce travail et Thibaud Decaëns pour sa disponibilité et son aide utile et appréciée. Philippe Le Gall et Bruno Mériguet sont également remerciés pour leurs ultimes corrections.

\section{RÉFÉRENCES}

Agudelo Rondon A. A., Lombardo F. \& Jantsch L. J. 2007. Checklist of the Neotropical mantids (Insecta, Dictyoptera, Mantodea). Biota Colombiana 8 (2): 105-158.

Agudelo Rondon A. A., Maldaner C. \& Rafael J. A. 2019. - Dry leaf or twig mantis? A new genus and species of Acanthopidae with sexually dimorphic cryptic strategies (Insecta: Mantodea). Zootaxa 4560 (2):331-344. https://doi.org/10.11646/zootaxa.4560.2.6

Agudelo Rondon A. A. \& Rivera J. 2015. - Some taxonomic and nomenclatural changes in American Mantodea (Insecta, Dictyoptera) - Part I. Zootaxa 3936: 335-356. https://doi. org/10.11646/zootaxa.3936.3.2

Audinet-Serville J. G. 1831. - Revue méthodique des Insectes de l'ordre des Orthoptères. Crochard, Paris, 101 p. (Coll. Annales 
des Sciences naturelles).

BEIER M. 1935. - Mantodea, Fam. Mantidae, Subfam. Mantinae, in WYTSMAn P. (éd.) Genera Insectorum 203. T'Kint, Bruxelles: 154.

Bellanger Y., Lelong P. \& Jourdan T. 2018. - A new Phasmatodea for French Guiana, Creoxylus paradoxus (Kirby, 1904), and notes on the stick-insects of Réserve naturelle nationale de la Trinité. Bulletin de la Société entomologique de France 123 (2): 273-281.

BRANNOCH S. K., WiEland F., RivERA J., KLASS K. D., BÉTHOUX O. \& SVENSON G. J. 2017. — Manual of praying mantis morphology, nomenclature, and practices (Insecta, Mantodea). ZooKeys 696: 1-100. https://doi.org/10.3897/zookeys.696.12542

Brôlé S. \& Touroult J. 2014. - Insects of French Guiana: a baseline for diversity and taxonomic effort. ZooKeys 434: 111130. https://doi.org/10.3897/zookeys.434.7582

BurmeIster H. 1838. - Handbuch der Entomologie. II. Band: Besondere Entomologie. II. Abtheilung. I. Hälfte. vulgo Orthoptera. Theodor Christian Friedrich Enslin, Berlin, 756 p.

Charles-Dominique P. 2011. - Guyane. Milieux, faune, flore. CNRS éditions, Paris, 224 p.

Chopard L. 1910a. - Description d'un Mantide nouveau de la Guyane française. Bulletin de la Société entomologique de France 9: $182-185$

ChOpard L. 1910b. - Description de deux espèces nouvelles de Thespis Serv. de la Guyane française. Bulletin de la Société entomologique de France 15: 272-275.

CHOPARD L. 1912. - Contribution à la Faune des Orthoptères de la Guyane française (1 ${ }^{\text {er }}$ mémoire. Mantidae et Phasmidae). Annales de la Société entomologique de France 80 (1911): 315-350.

EHRMANn R. 2002. - Mantodea Gottesanbeterinnen der Welt. Natur und Tier-Verlag, Münster, 519 p., 32 pl.

FABRICIUS J. C. 1787. - Mantissa Insectorum sistens eorum species nuper detectas. Hafniae, Copenhague: $20+348$ p. https://doi. org/10.5962/bhl.title.36471

FABRICIUS J. C. 1793. - Entomologia systematica emendate et aucta. Hafniae, Copenhague: viii $+519 \mathrm{p}$.

FABRICIUS J. C. 1798. - Supplementum Entomologiae systematicae. Hafniae, Copenhague: ii + 572 p.

FranÇOIS A. \& RoY R. 2015. — Le genre Microphotina Beier, 1935: deux espèces ou une seule? (Mantodea, Photinaidae). Bulletin de la Société entomologique de France 120 (3): 389-396.

Gargominy O., Tercerie S., Regnier C., Ramage T., Dupont P., DASZKIEWICZ P. \& PONCET L. 2019. - TAXREF v13, référentiel taxonomique pour la France: méthodologie, mise en ouvre et diffusion. Muséum national d'Histoire naturelle, Paris, 63 p. (Rapport Patrinat).

Giglio-Tos E. 1927. - Orthoptera - Mantidae. Das Tierreich, $50, \mathrm{xl}+707$

Gombauld P., Duranton M., Garrouste R., Lupoli R., Béranger J.-M., Champenois J.-P., Camus D., Cerdan P., Degallier N., Feer F., Bénéluz F., Faynel C., ThiaucourtP., Gibernau M., Barabé D., Rabarison P., Corbara B., Dejean A., Orivel J. \& Horeau V. 2004. - Insectes de Guyane: Beauté et diversité. SEPANGUY, 170 p. (Collection Nature Guyanaise, Cayenne).

Hajibabaei M., DewaARd J. R., IVAnova N. V., Ratnasingham S., Dooh R. T., Kirk S. L., Mackie P. M. \& Hebert P. D. N. 2005. - Critical factors for assembling a high volume of DNA barcodes. Philosophical Transactions of the Royal Society B Biological Sciences 360: 1959-1967. https://doi.org/10.1098/rstb.2005.1727

Hebert P. D. N., Penton E. H., Burns J. M., Janzen D. H. \& HALLWACHS W. 2004. - Ten species in one: DNA barcoding reveals cryptic species in the neotropical skipper butterfly Astraptes fulgerator. Proceedings of the National Academy of Sciences of the United States of America 101: 14812-14817. https:// doi.org/10.1073/pnas.0406166101

Hsien T. C., Ma K. H. \& CHAO A. 2014. - iNEXT: An R package for interpolation and extrapolation in measuring species diversity. $R$ Development Core Team. 2004. $R$ : a language and environment for statistical computing. R Foundation for Statistical Computing, Vienna, Austria.

IVANOVA N. V., DeWAard J. R. \& Hebert P. D. N. 2006. - An inexpensive, automation-friendly protocol for recovering highquality DNA. Molecular Ecology Notes 6: 998-1002. https://doi. org/10.1111/j.1471-8286.2006.01428.x

JanTSCH L. 1999. - Estudos filogenéticos em Mantódeos americanos (Insecta: Pterygota: Mantodea). PUCRS, Doutorado, Porto Alegre, $138 \mathrm{p}$.

Jourdan T., LELONG P. \& Bellanger Y. 2014. - Contribution à l'inventaire des Phasmatodea de Saül, Guyane. Bulletin de la Société entomologique de France 119 (4): 487-498.

KirbY W. F. 1904. - A Synonymic Catalogue of Orthoptera. Vol. I. Orthoptera Euplexoptera, Cursoria et Gressoria. British Museum, London, 1: I-X, 1-501.

La Greca M. \& Lombardo F. 1989. - Mantodei Neotropicali. I. Il genere Mantoida con descrizione di due nouve specie. Animalia 16: 55-67.

LOMbardo F., Umbriaco R. \& IpPOLITO S. 2015. - Taxonomic revision of the Neotropical genus Parastagmatoptera Saussure, 1871 (Dictyoptera, Mantidae, Stagmatopterinae) with a biogeographic comment. Insect Systematics \& Evolution 46: 221-267. https://doi.org/10.1163/1876312X-45032117

Lupoli R. 2019. - The genus Phalaecus Stål, 1862 in French Guiana, description of P. carmini n. sp., and the female of P. lineatus Grazia, 1983 from Mitaraka (Hemiptera: Pentatomidae), in Touroult J. (éd.), "Our Planet Reviewed" 2015 large-scale biotic survey in Mitaraka, French Guiana. Zoosystema 41 (3): 21-28. https://doi.org/10.5252/zoosystem-a2019v41a3

MERIAN M. S. 1730. - Over de voortteeling en Wonderbaerlyke veranderingen der Surinamsche Insecten. J. F. Bernard, Amsterdam, 51 p.

Mortelmans J. \& Pollet M. 2018. - New data and species of Thecomyia Perty, 1833 (Diptera: Sciomyzidae) from Mitaraka (French Guiana), with notes on the genus, in TOuROulT J. (éd.), "Our Planet Reviewed" 2015 large-scale biotic survey in Mitaraka, French Guiana. Zoosystema 40 (17): 415-423. https:// doi.org/10.5252/zoosystema2018v40a17

Olivier A. G. 1792. - Histoire naturelle Insectes. Encyclopédie méthodique 7. Mantes. Panckoucke, Paris: 616-642, pl. 132-133.

Otte D. \& Spearman L. 2005. — Mantida Species File. Catalog of the mantids of the World. Insect Diversity Association, Publication Number 1, Philadelphia, 489 p.

Pascal O., Touroult J. \& Bouchet P. 2015. - Expédition "La Planète Revisitée" Guyane 2014-2015, Synthèse des premiers résultats. Muséum national d'Histoire naturelle, Pro-Natural International, Paris, $218 \mathrm{p}$.

Puillandre N., Lambert A., Brouillet S. \& Achaz G. 2012.ABGD, Automatic Barcode Gap Discovery for primary species delimitation. Molecular Ecology 21: 1864-1877. https://doi. org/10.1111/j.1365-294X.2011.05239.x

QuARTAROLlO G. \& BAGLAN A. 2016. — Les poissons de la Noussiri: inventaire de l'ichtyofaune d'un affluent de l'Oyapock (Guyane française). Les cahiers de la foundation Biotope 4: 1-21.

R Development Core Team 2004. - $R$ : a language and environment for statistical computing. R Foundation for Statistical Computing, Vienna, Austria.

RATNASINGHAM S. \& HEBERT P. D. N. 2007. — BOLD: The Barcode of Life Data System (www.barcodinglife.org). Molecular Ecology Notes 7: 355-364. https://doi.org/10.1111/j.14718286.2007.01678.x

RatNASingham S. \& HeBerT P. D. N. 2013. - A DNA-Based Registry for All Animal Species: The Barcode Index Number (BIN) System. PLoS ONE 8 (8): e66213. https://doi.org/10.1371/ journal.pone.0066213

Rivera J. \& SVENSON G. J. 2016. — The Neotropical 'polymorphic earless praying mantises' - Part I: molecular phylogeny and revised higher-level systematics (Insecta: Mantodea, Acanthopoidea). Systematic Entomology 41: 607-649. https://doi.org/10.1111/syen.12178 
Rodrigues H. M. \& Cancello E. M. 2016. - Taxonomic revision of Stagmatoptera Burmeister, 1838 (Mantodea, Mantidae, Stagmatopterinae). Zootaxa 4183 (1): 1-78. https://doi. org/10.11646/zootaxa.4183.1.1

Roy R. 2002a. - Commentaires à propos du genre Plesiacanthops Chopard, 1913 et redescription d'Acanthops tuberculata Saussure, 1870 [Dictyoptera, Mantodea]. Revue Française d'Entomologie 24 (4): 171-177.

Roy R. 2004. - Révision et phylogénie des Choeradodini Kirby, 1904 (Dictyoptera, Mantidae). Bulletin de la Société entomologique de France 109 (2): 113-128.

RoY R. 2006a. - Vue d'ensemble sur les Acontistinae Giglio-Tos, 1919 (Dictyoptera, Acanthopidae). Bulletin de la Société entomologique de France 111 (3): 327-338.

Roy R. 2006b. - Metriomantis pilosa (Chopard, 1912), bona species (Dict., Mantidae). Bulletin de la Société entomologique de France 111 (4): 538.

RoY R. 2010. - Contribution à la connaissance du genre néotropical Mantoida Newman, 1838 (Dict., Mantoididae). Bulletin de la Société entomologique de France 115 (1): 22.

Roy R. 2015. - Un nouveau genre de Mante de Guyane française (Mantodea, Acanthopidae). Bulletin de la Société Entomologique de France 120: 143-146.

RoY R. 2019. - Les Mantes (Dictyoptera, Mantodea) du massif du Mitaraka (Guyane), in TOUROUlT J. (éd.), "Our Planet Reviewed” 2015 large-scale biotic survey in Mitaraka, French Guiana. Zoosystema 41 (5): 59-70. https://doi.org/10.5252/ zoosystema2019v41a5

Roy R. \& EHRMANN R. 2009. - Révision du genre Zoolea Audinet-Serville [Mantodea, Mantidae, Vatinae]. Revue française d'Entomologie (N.S.) 31 (1): 1-22.

Saussure H. 1869. - Essai d'un système des Mantides. Mittheilungen der Schweizeischen Gesellschaft 3 (2): 49-73.

SAUSSURE H. 1871. - Mélanges orthoptérologiques, IIIe fascicule, IV Mantides. Mémoires de la Société de Physique et d'Histoire naturelle de Genève 21 (1): 1-215, 54 fig.

Saussure H. \& Zehntner L. 1894. - Biologia Centrali. Americana - Insecta-Orthoptera-Mantidae. Bormans, 1: 123-197.

SCHWARZ C. J. \& RoY R. 2019. - The systematics of Mantodea revisited: an updated classification incorporating multiple data sources (Insecta: Dictyoptera). Annales de la Societé entomologique de France (N.S.) 55 (2): 101-196. https://doi.org/10.1080/003 79271.2018 .1556567

STOLL C. 1787. - Naturlijke en naar leven nawwerkeurige gerkleurde afdeeldingen en beschrijvingen der spoken, wandelende bladen, zabelspringhanen, kredels, trekspringhanen en kakkerlaken. In alle vier deelen del wereld Europa, Asia, Afrika en Amerika = Représentation exactement colorée d'après nature des spectres ou phasmes, des mantes, des sauterelles, des grillons, des criquets et des blattes qui se trouvent dans les quatre parties du monde, l'Europe, l'Asie, l'Afrique et l'Amérique. J.C. Sepp et fils, Amsterdam, 9+56 p., 18 pl.

SVENSON G. J. 2014. - Revision of the Neotropical bark mantis genus Liturgusa Saussure, 1869 (Insecta, Mantodea, Liturgusini). Zookeys 390: 1-214. https://doi.org/10.3897/zookeys.390.6661

Svenson G. J. \& Branham M. A. 2007. - Photinini LeConte, 1881 (Insecta, Coleoptera) and Photininae Giglio-Tos, 1915 (Insecta, Mantodea): proposed resolution of homonymy between family-group names. Bulletin of Zoological Nomenclature 64 (4): 243-251.

SVEnSON G. J. \& Whiting M. F. 2009. - Reconstructing the origins of praying mantises (Dictyoptera, Mantodea): the roles of Gondwanan vicariance and morphological convergence. Cladistics 25: 468-514. https://doi.org/10.1111/j.1096-0031.2009.00263.x

SVENSON G. J. \& Rodrigues H. M. 2019. - A novel form of wasp mimicry in a new species of praying mantis from the Amazon rainforest, Vespamantoida wherleyi gen. nov. sp. nov. (Mantodea, Mantoididae). PeerJ7: e7886. https://doi.org/10.7717/peerj.7886

Svenson G. J., Medellín C. \& Sarmiento C. 2016. - Reevolution of a morphological precursor of crypsis investment in the newly revised horned praying mantises (Insecta, Mantodea, Vatinae). Systematic entomology 41: 229-255. http://doi. org/10.1111/syen.12151

TAVAKILIAN G. 1993. - L'entomofaune de la forêt guyanaise. Congrès SEPANGUY, ORSTOM, Cayenne, 5 p.

Terra P. S. 1995. - Revisão Sistemática dos Géneros de Louvaa-Deus da Região Neotropical (Mantodea). Revista Brasileira de Entomologia 39 (1): 13-94

Touroult J., Pollet M. \& Pascal O. 2018. - Overview of Mitaraka survey: research frame, study site and field protocols, in Touroult J. (éd.), "Our Planet Reviewed" 2015 large-scale biotic survey in Mitaraka, French Guiana. Zoosystema 40 (13): 327-365. https://doi.org/10.5252/zoosystema2018v40a13

Vedel V., Rheims C., Murienne J. \& Brescovit A. D. 2013. Biodiversity baseline of the French Guiana spider fauna. SpringerPlus 2: 361. https://doi.org/10.1186/2193-1801-2-361

WESTWOOD J. O. 1889. - Revisio Insectorum familiae Mantidarum, speciebus novis aut minus cognitis descriptis et delineatis. Gurney and Jackson, London, 54 + iii p., 14 p. h.t.

WiELAND F. \& SCHÜTTE K. 2011. - Unrecognized museum specimen expands distribution of Mantoida (Insecta: Mantodea) into the central Caribbean. Entomologische Mitteilungen aus dem Zoologischen Museum Hamburg 15 (186): 305-315.

Soumis le 13 août 2019 accepté le 7 octobre 2019; publié le 26 février 2020. 